\title{
Regulation, Imperfect Competition, and the U.S. Abortion Market*
}

\author{
Andrew Beauchamp \\ Department of Economics \\ Boston College
}

October 2013

\begin{abstract}
The market for abortion in the U.S. has become increasingly concentrated in recent years, while many states have tightened abortion regulations aimed at providers. Using unique data on abortion providers I estimate an equilibrium model of demand, price competition, entry and exit, which captures the effect of regulation on the entire market. The estimates show that regulations played an important role in determining the structure and evolution of the abortion market. Counterfactual simulations reveal increases in demand-aimed regulation was the single most important observed factor explaining recent declines in abortion. Simulating Utah's strict regulatory regime over the sample period reveals that tightening abortion restrictions can actually increase the number of abortions in equilibrium, mainly through tilting the competitive landscape toward lower-priced providers.
\end{abstract}

${ }^{*}$ We thank Peter Arcidiacono, Joe Hotz, and Paul Ellickson, Andrew Sweeting, Jason Blevins, Alan Collard-Wexler, the editor, anonymous referees and seminar participants at Duke, Boston College, Notre Dame, Virginia and the 2010 Econometric Society Winter Meetings. We are especially grateful to the Alan Guttmacher Institute for data access. 


\section{Introduction}

The debate over abortion rights in the United States has continued mainly at the state level following the landmark decisions of Roe vs. Wade and Doe vs. Bolton in 1973 1 More recently governments in New York, California, Texas and Virginia have all made headlines by introducing controversial policies aimed at expanding or restricting the provision of abortion services. In New York and California laws allowing nonphysicians to perform (even surgical) abortions have been introduced and passed respectively $\left[^{2}\right.$ Meanwhile in Texas an out-right ban of abortions past 20 weeks was adopted, drawing national attention to a law-maker's effort at filibustering the bill $3^{3}$ And in Virginia the legislature came under fire nationally for the introduction of a bill requiring invasive ultrasounds for any prospective patient 4 Similar controversies stretch back to 1992.5 While it is unclear to what extent these policies and other laws which directly regulate abortion providers influence larger trends in abortion, we do know that regulations such as these have been on the rise. Figure 1 plots the percentage of U.S. states with any supply-side abortion regulation and the mean number of regulations per state through $20055^{6}$

Abortion incidence and the composition of providers have also both seen dramatic shifts since the early 1990's. The number of abortions in the U.S. has been falling since around 1990, as can be seen in the upper line in the left hand side of Figure 2.7 There has also been an increase in the number of procedures per provider, depicted by the lower line. Abortions in the United States are supplied by three types of organizations:

\footnotetext{
${ }^{1}$ These two cases established a framework of competing rights between a state's interest in protecting potential or prenatal life and a woman's right to privacy, life and health.

${ }^{2}$ In California bill AB 154 passed both houses and went to the Governors desk in September 2013. The New York bill, S 438 (Stewart-Cousins), although supported by the Governor was subject to infighting and upheld in summer 2013.

${ }^{3}$ The restriction was signed in to law July, 18 2013, despite the filibuster of State Senator Wendy Davis on June 252013 (New York Times, July 18 2013).

${ }^{4}$ The Virginia law was modified to require less invasive ultrasounds and signed into law in March 2013 (USA Today, March 7 2013).

${ }^{5}$ Planned Parenthood vs Casey introduced the possibility of more stringent state-level restrictions following the point of fetal viability, replacing the prior "trimester" divisions of individual and states rights.

${ }^{6}$ Supply-side regulations here include: providers having a medical license, being a state certified OB/GYN, physical/administrative requirements (such as those in VA and TX), locating within a certain physical distance from hospitals, and maintaining admission or emergency agreements with local hospitals.

${ }^{7}$ The abortion rate (abortions over women aged 15-44) and ratio (abortions over pregnancies) have seen very similar declines.
} 
hospitals, specialized clinics, and non-specialized providers such as private physicians' offices, which refer to as non-hospital, non-clinic (NHNC) providers. The right hand panel of Figure 2 plots the number of providers in the U.S. for each type across time. The number of hospital providers declined steeply from the late 1970s onward reflecting a shift from hospitals serving as a major provider of all types of abortion to playing a specialized role after the early 1980s 8 The NHNC providers experienced a dramatic wave of exits beginning in the early 1990s, and by 2000 the number of active providers had fallen by $50 \%$ over its 1990 level. Meanwhile more specialized abortion clinics maintained stable numbers while serving more patients.

This paper links these two recent trends to understand what role abortion regulation played in recent declines in abortion and providers, and how alternative policies would have changed the historical evolution of the U.S. abortion market. To answer these questions we propose and estimate an equilibrium model of demand, price competition, entry and exit among the three types of providers. The approach disentangles how regulation altered demand, fixed and variable costs, and allows the simulation of the market under different counter-factual policies. Although there is much prior work on abortion regulation, it usually addresses the impact on abortion of "demand-aimed" policies like public funding and parental consent laws.99 Relatively little is known about the effects of direct regulation of abortion providers, or how regulation interacts with market fundamentals such costs and strategic interaction 10 Since supply-aimed regulation potentially affects long-term profitability and competition, we estimate a dynamic model allowing us to examine how past regulation determines current and future market structure.

The approach adds to the growing literature on estimating dynamic models of imperfect competition, notably Bajari, Benkard and Levin (2007), Ryan (2012) and

\footnotetext{
${ }^{8}$ There was also a large secular decline in the number of hospitals in the U.S. over the period. Looking only at markets which saw few overall hospital closings the trend away from hospital abortion provision is still dramatic. Hospital abortions accounted for $46 \%$ in 1973 , declining to $18 \%$ by $1982,7.3 \%$ in 1991 and $4.8 \%$ in 2005.

9 Haas-Wilson (1996), Levine, Trainor and Zimmerman (1996), Blank, George and London (1996), Bitler and Zavodny (2001), and Levine (2003) all measure the impact of state laws on abortion demand. Results vary depending on the fixed effects models estimated and the years used for estimation, and Medoff (2007) contains a review. In general findings are consistent with theory: public funding increases abortion ratios, restrictions such as parental consent reduce them. Studies such as Haas-Wilson (1996) examine impacts separately for minors, where she finds more pronounced effects.

${ }^{10}$ The only other work on this topic, Haas-Wilson and Lindberg (1999) suggests that larger clinics are better able to compete, consistent with large fixed cost.
} 
Collard-Wexler (2013). In the model non-hospital providers engage in Betrand-Nash price competition within metro-areas, optimizing their pricing decisions independently across periods and taking hospital demand as given. The result is a Markovperfect Nash Equilibrium (MPNE), consistent with the framework put forward by Ericson and Pakes (1995) for studying industry dynamics. Given expectations about per period demand and price competition, providers then make entry and exit decisions taking into account fixed costs of entry and operation.

To estimate the model we use a three-step approach. Firstly, we estimate a discrete choice model of abortion demand across the three types of providers. The demand estimates are then used express the marginal costs, which we estimate from the Bertrand-Nash first-order conditions. Finally, using these parameters and estimates of the conditional choice probabilities (CCPs) of entry and exit we can calculate per-period profits, using changes in the number of providers over time to estimate fixed costs of entry and operation 11 The eased computational burden from the multistep approach allows inclusion of time-varying serial correlation among unobserved demand, costs and profits, using the methods of Arcidiacono and Miller (2011).

The estimates reveal that regulations played an important role in determining the structure and evolution the abortion market. We find evidence that the most widely adopted and longest standing regulations aimed at providers, physician restrictions and abortion licensing, raised the marginal and fixed costs among NHNC's. In contrast we find no evidence that more recent and controversial restrictions appreciably reduce either the number of abortions or the number of providers. In the sample period these regulations are mainly adopted in places where abortion is declining and relatively infrequent. Meanwhile demand aimed regulations, primarily waiting periods and parental consent laws, reduced abortion demand significantly among clinics. Estimates from the demand model show that abortions are both price sensitive and that patients substitute across the different types of providers, a point which influences the long-term consequences of regulation. Incorporating heterogeneity is also important: we find fixed and marginal costs vary substantially in unobserved ways across markets, indeed in only one unobserved state (of the three incorporated) do provider revenues cover operation costs. We also find an important reason for the

\footnotetext{
${ }^{11}$ Applying an insight from the work of Hotz and Miller (1993) allows one to use one-step ahead conditional choice probabilities to completely characterize future value terms associated with the dynamic optimization problem.
} 
lack abortion access outside of profitable metro-areas is that entry barriers are large (roughly $\$ 7$ to $\$ 11$ million for clinics). We also find entry costs are higher cities with more religious populations: increasing by one standard deviation the number of religious adherents who are Catholics or Southern Baptists (the two largest groups with a history or protesting abortion) increases entry costs by $\$ 290,000$ for clinics.

An important question that has been largely un-addressed is the underlying cause of the large decline in abortion over the past two decades. Although researchers have pointed out declines in risky sexual behavior among youth 12 these behaviors are themselves not well understood, and conditioned on the underlying access to reproductive health. ${ }^{13}$ At the same time heated debates have continued over the appropriate level of regulation among reproductive health providers, with the result being a proliferation of new regulations as shown in Figure 2. We find that the most important single observed factor in explaining the decline in abortions was the increase in demand-aimed regulation over the period of the recent decline. Freezing all demand regulations at their 1991 levels explains more than $15 \%$ of the abortion decline between 1991 and 2005. In contrast, freezing the demographics in demand explains only $7 \%$ of the decline.

It is also the case that the dynamic impact of regulation is important since regulations raised the fixed costs of entry, meaning it takes years for their influence to play out in the market; reduced-form studies focusing on contemporaneous policy effects necessarily miss the long-term impact on the distribution of providers. A simulated repeal of regulation governing the supply-side of the market in 1991 shows that the abortion decline over the period is reduced by roughly $25 \%$, and that this effect takes time to materialize through the entry and exit among providers. The repeal of supply regulations (again in 1991) dramatically increases entry among NHNC providers: in 1992 their numbers overall increase by $3 \%$, but by 2005 , their numbers increase by $30 \%$. While the increase in providers is more concentrated in larger (and thus more profitable) markets which already have providers, it is also the case that supply-repeal increases access (defined as the fraction of markets with a provider) by nearly $7 \%$ in 2005. This is because supply-side regulation created a relatively large entry barrier in less profitable markets. In contrast repeal of demand aimed regulation has no current

\footnotetext{
${ }^{12}$ Santelli and Melnikas (2010) argues access to contraceptives is the most prominent reason for recent declines in teenage births (and abortions).

${ }^{13}$ Kane and Staiger (1996) show evidence that pregnancy is endogenous with respect to abortion clinic closings.
} 
or long-term impact on the fraction of metro areas without a provider.

Our model lets us address how the national market would have evolved under a strict regulatory regime, and the findings are counter-intuitive. We simulate the imposition of the regulatory regime of Utah from 1976 through 2005. Utah was one the most tightly regulated states over the sample period. We find that a strict policy (imposing licensing, physician restrictions, waiting periods and parental notification laws), actually increases the number of abortions observed overall, with moderate decreases in the number of providers. By imposing entry barriers among small providers, the Utah regulatory regime hastens their decline in the market, which generates changes in the competitive balance, allowing clinics to charge higher prices. This increased profitability leads to greater entry among clinics, which when combined with substitution toward hospitals, generates a net increase in abortion. Thus the effects of supply-aimed regulation are complicated by the dynamic competitive response of clinic providers and the availability of close substitutes for NHNC's among hospital providers.

The rest of the paper proceeds as follows. Section 2 discusses the unique data set on abortion providers and the state level restrictions over the period of interest. Section 4 presents the model of demand, competition, entry and exit, and Section 5 focuses on the estimation procedure and results. Finally Section 6 covers the policy simulations and Section 7 offers some final thoughts on regulation and abortion markets.

\section{Data}

The data used for analysis here come from a number of different sources and are listed in Table 1. The data on abortion providers comes from the Alan Guttmacher Institute (AGI) Survey of Abortion Providers, a periodic survey of all known abortion providers in the United States which began in 1973.14 We observe aggregated data

\footnotetext{
${ }^{14}$ See Henshaw and Van Vort (1994). AGI contacts all known providers from prior surveys, dropping those who closed or no longer offered abortion. They include questions on other providers in the local area and conduct phone book searches. Other listings used include the National Abortion Federation (NAF), Planned Parenthood and The National Abortion Rights Action League (NARAL), a national newspaper clipping service, and internet listings in later years. Beginning in 1992 AGI purchased commercial mailing listings relevant to abortion providers. Establishments not responding were followed up with phone calls, up to a dozen times in some cases. State health departments also keep records on establishments which were used for non-responders when available. Henshaw and Van Vort (1994) estimate they recorded at least $97 \%$ of the abortions conducted in 1992, with the
} 
at the county level on the total number of providers and total number of abortions, across three types of providers: hospitals, clinics and non-hospital non-clinic providers (NHNCs) ${ }^{15}$ To focus on market interactions we will aggregate the county data into 865 metropolitan statistical areas for which we observe a balanced panel of providers and abortions across 22 years ${ }^{16}$ Price data come as the within-county mean and standard deviation of prices among non-hospital providers, along with data on the number of respondents 17 These data are available for 7 years, and are only available for a subset of counties. Because our goal is to study markets we transform the countylevel price data into MSA-level data, separating out prices for clinics and NHNCs, via a procedure outline in the Appendix 18

The top panel of Table 2 shows the trends in the overall entry and exit across MSAs. Entry occurred among all the types of providers in the early 1970s, but between 1975 and 1985 the hospitals exits began, followed by a wave of exit among NHNC providers between 1985 and 2005. The market shares in market-years with greater than one thousand procedures show the increasing dominance of abortion clinics in the supply of abortion services ${ }^{19}$ The share of total procedures in the third panel shows that exit among hospitals coincided with growth in larger providers. The average number of providers among both types of non-hospital providers has been falling recently, a point which coincides with recent price increases. Consistent

potential missing abortions occurring at physicians offices and hospitals who provided an extremely small numbers of abortions.

${ }^{15}$ The divisions are a long-standing convention in abortion provider surveys, any provider offering more than 400 abortions in a year is referred to as a "clinic." Although the distinction is technically based on size, it is an effort to separate fundamentally different types of providers. Clinics maintain a focus on reproductive health (STI screenings, pregnancy tests, contraceptive prescriptions etc.), frequently provide abortions at later gestations than non-hospital non-clinic providers, and more often do things like advertise. We take these distinctions as given in the data, and note that the average size of NHNC providers is 130 abortions per year, while the average size of clinics is 1730 abortions per year. Thus largely different infrastructures, provider networks, and other inputs are required to operate the two types of providers.

${ }^{16}$ The metro-statistical definition includes micro-politan areas as well. The 70 MSA's excluded from analysis averaged less than 4000 abortions per year.

${ }^{17}$ The price used throughout, and most frequently reported, is that for an abortion at 10 weeks using local anesthesia.

${ }^{18}$ AGI descriptive reports covering the sample period showed non-clinic non-hospital providers charging uniformly higher prices than clinics, so we assume within each county there is a mixture distribution of prices from both types of providers. With these assumptions and using the mean, standard deviation, number of respondents and the fraction of non-hospital providers who are clinics in each county-year, we back out two observed prices for each county. We designate the two prices as a clinic (lower) and non-clinic (higher). Details are given in the Appendix.

${ }^{19}$ This set of market years contained $97 \%$ of abortions in our 22 years of data. 
with increases in concentration we see prices among NHNC providers rose more over time than for clinic providers ${ }^{20}$

Table 3 presents evidence on how the number and types of providers in a county interact with price means and standard deviations. The first column presents correlations between mean price and the number of the three types of providers, conditional on state and year fixed effects, the third column adds county fixed effects. The positive and negative correlations between the number of NHNC providers and clinics respectively show that the two different categorizations of providers charge different prices, and therefore we argue below must offer differentiated services given that we know the vast majority of abortions are paid-for out of pocket ${ }^{21}$ In the second and fourth columns the standard deviation of non-hospital prices responds to the number of small providers (and the number of hospitals), evidence that large providers have similar scale economies across markets, and so their number does not influence price dispersion in a meaningful way. Next in columns 5 and 6, we estimate MSA-level price level-regressions which allow us to separate prices for NHNC's and clinics and then exam how the different providers price in response to competition. In column (5), conditioning on MSA and year fixed effects, we see that an increase in the number NHNC providers puts significant downward pressure on prices of clinic providers. Importantly an increase in the number of clinics shows no such downward pressure. In column (6) we similarly see no significant evidence downward pressure on prices of NHNC's from other NHNCs. Overall the correlations in the data show evidence of differentiated services competition across provider types, with little evidence of direct competition within provider types.

\footnotetext{
${ }^{20}$ These separate price trends are backed out from changes in the standard deviation and share of clinics among non-hospital providers.

${ }^{21} \mathrm{~A}$ summary is presented in Henshaw and Finer (2003) who found in a sample 637 non-hospital providers nearly $75 \%$ of abortions were paid for out of pocket. $62 \%$ of patients were paying full price out-of-pocket, $12 \%$ paid a reduced fee out-of-pocket, $13 \%$ had the procedure billed directly to their private insurance company, another $13 \%$ had the procedure funded through state medicaid agencies. Given the historically slow rate at which private insurers adopted abortion into their coverage plans, the percent paid out of pocket was higher in the past. Large populations within the U.S. are expressly prohibited from having abortions paid for by insurance, including all federal employees, military members and state employees in 12 states. Another 5 states expressly prohibit all private insurers from covering abortion, and insurance policies covering abortion must be purchased with an additional rider and payment of an extra premium in these states.
} 


\section{$2.1 \quad$ State Laws}

State level restrictions on providers take a variety of forms. Most recently, regulations termed TRAP (Targeted Regulation of Abortion Providers) laws have been passed. Along with TRAP laws many states have physician and license requirements, as well as regulations of later term procedures, requiring they be performed in or around hospitals. The wording of the laws varies across states, but laws are categorized into six major groups 22

The staggered implementation of the six groups of legislation are compiled in Table 4. States impose license requirements on providers in two ways ${ }^{23}$ The first column, denoted "License," refers to requiring a state-issued license to operate, along with an accompanying annual fee ${ }^{24}$ The second column contains enactment dates for laws restricting abortion provision to only physicians licensed to practice medicine in the state. Some laws also restrict practice to board certified OB/GYNs. Implicit in the physician laws are restrictions on nurse practitioners and physicians' assistants performing abortions, an issue which lead to the reversal of these laws in two states over the time period. Provider regulations involving hospital requirements are in columns 3-5 of Table 4. The second trimester laws require facilities performing second trimester abortions be licensed as outpatient surgical centers. The hospital location and agreement laws respectively require providers locate within a certain distance from, or maintain a written agreement with, a local hospital. Written agreements often detail admission procedures and privileges in case of an emergency. The final group of restrictions is termed "Physical and Administrative." They require providers to make explicit capital or labor expenditures. Examples include owning an ultrasound machine or regulating the size of the procedure room, facility, hallways, parking lot and/or waste disposal (e.g. AK, SC). These laws can also involve hiring staff: medical directors with experience and who maintain OB/GYN board certification

${ }^{22}$ The primary source for these data on regulations is the National Abortion Rights Action League (NARAL) state report cards, which generally include the legislative codes and relevant judicial histories. Some dates of enactment or revision were unclear and so I followed up on these cases by examining the state legislation or health code as necessary.

${ }^{23}$ The table excludes the seven states and Washington DC which had no such regulations over the time period, although these ares are included in estimation.

${ }^{24}$ The licensing fee charged varies from state to state but was unobserved for many states and so is not used in the analysis. The nominal fee is likely just one part of economic costs which providers must pay to obtain the license, such as record keeping and filling out applications, (which is often specifically mentioned in the statutes). 
(e.g. AL), and counselors or social workers with graduate degrees in specific subfields (e.g. CT). These laws generate the most controversy and publicity.

\subsection{Reduced Forms Policy Impacts and Endogeneity}

How does regulation influence prices? Table 5 shows the impact of policies on the number abortions and prices charged; regulations affected both quantities and prices for NHNC providers. The quantity regressions are Tobit models, which include all markets. ${ }^{25}$ Restrictions on location and which physicians can perform abortions show significant negative effects for small providers. Physical and administrative requirements to appear to burden clinics and lead to an increase in services provided by smaller providers who may either: (1) satisfy the requirements already or (2) not be subject to the same regulation. The coefficient for maintaining agreements with hospitals is consistent with shifts in the provision of abortions away from hospitals. Prices were also affected by regulation, again with small providers being more sensitive than clinics. All the estimates in Table 5 show effects combining the number of providers in the market, the extent of competition, and demand. The model below will allow us to disentangle the policy effects along these three avenues, presenting a clearer picture of how the market responded to regulation.

How did regulation influence the entry and exit of providers? Table 6 presents estimates from reduced-form models which use information on changes in the number of providers over time to separately identify entry and exit probabilities from observed time series on the total number of providers in a market. Since the likelihood for such a mixture is fairly complex, it is delayed until we present a full model of entry and exit below. This reduced form model assumes a logit shock at the firm level for entry and exit, and integrates out over all potential combinations of incumbents and entrants ${ }^{26}$ Estimates show that for NHNCs, licensing and physician restrictions both reduced entry, and physician restrictions were negatively related to staying in the market. Results for clinics show alternating significant signs for entry and incumbency. This suggests some policies help to stabilize the turnover in the market (physician restric-

\footnotetext{
${ }^{25} \mathrm{An}$ important difference between the data used here and prior studies are within-state observations; while allowing one to control for common state-specific unobservables they also reveal that many markets have no providers. Tobit models deal with this to some extent, but formal model below will rationalize these zero markets and their time paths with changing entry costs and demand.

${ }^{26}$ This also requires assumptions on the number of potential entrants, which we scale down from population.
} 
tions and hospital locations) or depreciated incumbent investments and lead to more entry (second trimester hospital restrictions and agreements with hospitals). These latter policies likely served to move more complicated and expensive procedures out of clinics and into hospitals.

Policy endogeneity can take two forms in this context. One concern is rising anti-abortion sentiment prior to a policy being enacted. Alternatively, policy makers could be responding to rising abortion use by trying to regulate suppliers. As a test of whether policy changes are being driven by changing unobservables, I regress policy enactment on the number of lagged abortions by provider type. I do so with and without the full state vector used in they dynamic model below. These include state fixed effects and state-specific linear trends. Also included are data from the Church and Church Membership Survey on the total number of religious adherents, and Catholics and Southern Baptists, the two largest groups which historically opposed abortion through political organizing. The results are presented in Table 7 for policies with significant correlation between lagged abortions and enactment.

Estimates show that without controlling for the vector of market specific information, state fixed effects and trends, the policy changes have a strong relationship to lagged sentiment (measured with lagged abortion). As the number of abortions at clinics increases, the likelihood of enactment increases, suggesting policy makers are responding to rising abortion rates ${ }^{27}$ After controlling for the state vector, all the coefficients in Table 7 shrink or change signs, and none are significant save public funding. Funding has been the most controversial and debated policy. Therefore we argue below that using conditional variation in enactment dates to identify policy effects captures their impact on demand and costs.

\section{From The Data to the Model}

Examining data from other sources we can see that in reality the three types of providers usually maintain different gestational limits and charge different prices. Henshaw and Finer (2003) show, using data extracted from the same master-file as our data, that in 2001 clinics were the most likely to offer services until 17 weeks of gestation, while the majority of NHNCs cease providing services at 12 weeks. After 17 weeks in the later half of the sample period, hospitals are most likely to provide

\footnotetext{
${ }^{27}$ The sign difference between NHNC and clinic effects suggests either the visibility of clinics triggers enactment, or that states with more small providers have lower absolute levels.
} 
services, which usually involved health risks or fetal abnormalities. Reports from the 1980's show gestational limits for the hospitals similar to those of clinics ${ }^{28}$ Data drawn from CDC Abortion Surveillance reports between 1972-2004 shows the percent of all abortions performed prior to 12 weeks has remained near 90\%. Only in 2004 was there a noticeable increase in the number of medical abortions 29 There has been a small increase in late-term abortions following 1990, which may reflect better testing for genetic conditions. Reports throughout the sample period show NHNC providers charge higher prices than clinics, with an average premium around $\$ 200$ in 2005 constant dollars, which is consistent with average gap we back out from our procedure for distinguishing NHNC and clinic prices.

Given these details on how providers operate on would like gestation and provider specific quantity and price data over time, but these data do not exist. The differentiation among procedures is along at least two dimensions: the gestational age, and factors associated with the type of provider. Provider characteristics such as proximity, familiarity, safety and the availability of prescription abortion help explain demand for higher priced NHNCs and hospitals. Given that these two dimensions of differentiation are correlated and that we only observe aggregates by provider type, we model the differentiation as being across the type of provider. The model below assumes a woman living in an MSA has a choice among four options: an abortion at a hospital, at an NHNC provider, at a clinic, or not obtaining an abortion in that market 30

As noted above we use MSAs to define markets since the estimation approach will require non-overlapping, independent markets. Individuals crossing state lines has been a concern in measuring abortion policy impacts. Blank, George and London (1996) examine neighboring state policies and find no impact of minor restrictions, but find the number of abortions performed on out-of-state residents increases with the number of providers. However, these prior findings are hindered by the geographic specificity of the data: cross-state travel in a many locations is also within-metro

\footnotetext{
${ }^{28}$ Henshaw, Forrest and Baine (1984). Data show hospital abortions accounted for $46 \%$ in 1973 , declining to $18 \%$ by $1982,7.3 \%$ in 1991 and $4.8 \%$ in 2005 .

${ }^{29}$ The term medical groups a number of procedures including hysterectomies, but the recent rise comes from the impact of RU-486 on the market. RU-486 was approved by the FDA in 2000. The "morning after pill" or emergency contraception is not accounted for in abortion data.

${ }^{30}$ The outside option therefore includes travel to some other market as well, which is not made explicit given that lack of detail about a woman's place of residence.
} 
area travel ${ }^{31}$ The MSA market definition helps to alleviate this concern ${ }^{32}$ Kane and Staiger (1996) addresses how the distance to the nearest provider affects abortion. Consistent with an endogenous pregnancy model, they find that as the distance increases birth rates fall. We model search costs (and other indirect costs) by including polynomials of the number of each type of provider in patient demand.

Finally, there are concerns about discounted pricing and insurance when using listed abortion prices. As noted above, most women pay out of pocket. Also, there are factors within households that often make using insurance coverage for abortion undesirable. For example, women insured through spousal or parental coverage who desire to terminate their pregnancy without family members knowing must often avoid insurance coverage and pay out-of-pocket 33 We note that price variation occurs mainly across markets in the same state, so most discounting (e.g. through Medicaid funding and state-level charities) is controlled for. We also allow price sensitivity to vary with unobserved heterogeneity in the demand model. Since we do not observe prices for the entire sample, we outline a demand model below in which all the relevant parameters can be estimated on a subset of markets. Finally since we do not observe hospital prices, we only model the hospital supply side in a reduced form fashion, and utility from a hospital procedure does not explicitly include price. ${ }^{34}$

\section{Empirical Model}

Following the work of Ericson and Pakes (1995) our model is divided into three components: (1) a discrete choice model of abortion demand, (2) static competition in services given the number of participants and (3) dynamic choices over whether to enter or exit which determine the number of providers in the following period. The stage game is Bertrand-Nash price competition among NHNC providers and clinics, taking the hospital share as given from demand. Since we do not observe any withinprovider-type information (e.g. provider specific quantities among clinics) we assume symmetry of demand served and profits 35

\footnotetext{
${ }^{31} \mathrm{CDC}$ data show that Washington D.C. has generally been the leader in the fraction of abortions obtained by out of state residents.

${ }^{32}$ Border MSAs' policies are measured with a population weighted index between zero and one.

${ }^{33} \mathrm{CDC}$ data show that between $18-23 \%$ of women obtaining abortions were married and between $52-65 \%$ were under the age of 25 for most of the sample period.

${ }^{34}$ In more recent years many more hospital abortions were covered by insurance since they normally involved health risks or fetal abnormalities, consistent with the demand model.

${ }^{35}$ See Ryan (2012).
} 


\subsection{Demand}

We follow Berry (1994) in outlining a nested-logit demand model for differentiated services, which can be estimated using market-level data. Let $m$ denote the market a provider is operating in, $j$ the type of provider (Clinic, NHNC or hospital), and $k$ the unobserved type of market. An individual agent $i$ then receives utility of the form:

$$
u_{i j m k}=\beta_{0 j k}+X_{m}^{\prime} \beta_{j}-\alpha_{k} P_{j m}+\xi_{j m}+\varepsilon_{i j m}
$$

with observed utility from the outside choice normalized to zero. The $\xi_{j m}$ is viewed as the mean of individuals' valuation of unobserved provider characteristics (e.g. proximity, safety, anonymity, etc.), and $\varepsilon_{i j m}$ captures the distribution of preferences about the mean ${ }^{36} \varepsilon_{i j m}$ is independent and identically distributed across individuals and markets but not choices. Instead the three abortion choices are placed within a nest and share a component of unobserved utility governed by correlation parameter $\lambda_{k}$. The observables $X_{m}$ include demographics, (all) regulations, characteristics of healthservices, state-fixed effects, region-trends, and polynomials in the number of abortion providers of each type which allow for distance and other indirect costs to affect individual utility. This choice model allows for more flexible substitution patterns following changes to observables $\left\{X_{m}, P_{j m}\right\}$, than the logit model, but still maintains that price elasticities are driven by market-shares, a feature we exploit later to infer prices because we only observe a subset of prices. The market-level unobserved heterogeneity is allow to shift demand for each type of provider $\left(\beta_{0 j k}\right)$, influence the price elasticity $\alpha_{k}$, and the degree of substitution between abortion and the outside option $\lambda_{k}$.

As Berry (1994) showed, because we have closed form for choice probabilities under the nested-logit distribution, we can express choice probabilities as shares via the following linear expression:

$$
\log \left(S_{j m}\right)-\log \left(S_{0 m}\right)=\beta_{0 j k}+X_{m}^{\prime} \beta_{j}-\alpha_{k} P_{j m}+\left(1-\lambda_{k}\right) \log \left(S_{j m \mid G}\right)+\xi_{j m},
$$

where $S_{j m \mid G}$ is the share of abortions performed by provider type- $j{ }^{37}$ Because $\xi_{j m}$ represents unobserved provider characteristics it is likely correlated with price. Using

\footnotetext{
${ }^{36}$ Here $\xi_{j m}$ is market-choice specific, similar to the model of Nevo (2001).

${ }^{37}$ This formulation comes from taking the $\log$ of the choisce probability for $j$ and re-arranging terms.
} 
instruments for $\left\{P_{j m}, S_{j m \mid G}\right\}$ we can estimate (2) via two-stage least squares. By incorporating a weighting matrix we can estimate $\left\{\beta_{j k}, \alpha_{k}, \lambda_{k}\right\}$ using weighted twostage least squares.

\subsection{Pricing and Mark-ups}

The optimal pricing rule for a non-hospital provider in market $t$ comes from the following profit maximization condition:

$$
\max _{P_{j m}} \quad \pi_{j m}=\frac{1}{N_{j m}} S_{j m}\left(P_{j m}, P_{j^{\prime} m}, X_{m}\right)\left(P_{j m}-M C_{j m}\right),
$$

where $S_{j m}$ is the share of individuals choosing provider type $j$ and $1 / N_{j m}$ comes from symmetry across firms within a provider-type. $M C_{j m}$ captures common marginal costs shared by providers of a given type $j$ within a market, and consists of both observed and unobserved components: $\log \left(M C_{j m}\right)=Z_{j m}^{\prime} \gamma_{j k}+\nu_{j m}$. This specification of profit assumes all providers profit maximize. Without provider level data we cannot model non-profit behavior. If all clinics behaved as non-profits, then parameter estimates in $M C_{j m}$ can simply be re-interpreted as provider utility. The potential issue is whether national organizations like Planned Parenthood engage in profit sharing among their affiliates, which would influence the relationships assumed in the model between providing services and the costs of doing so. There is no evidence of this. Information from Planned Parenthood annual reports show revenue flows the opposite direction: the national organization receives income from affiliates, providing some services such as policy advocacy on behalf of local affiliates 38 Additionally if abortion clinics cross subsidize other services (pregnancy testing, contraceptive services and STD testing), from abortion revenue, they have incentives to profit maximize. ${ }^{39}$

With the profit function defined in (3), we can express the price-markup relationship as:

$$
P_{j m}-M C_{j m}=\frac{S_{j m}\left(P_{j m}, P_{j^{\prime} m}, X_{m}\right)}{\frac{\partial S_{j m}\left(P_{j m}, P_{j^{\prime} m}, X_{m}\right)}{\partial P_{j m}}},
$$

\footnotetext{
${ }^{38}$ Based on calculations from Planned Parenthood balance sheets in 2011, affiliates (as distinct from the national organization which performs no abortions) received only $17 \%$ of their revenue from donations.

${ }^{39}$ Planned parenthood has seen numerous state-level efforts to de-fund is provision of contraceptives. Clinics may cross subsidize if for instance government payments for the provision of contraceptives do not cover all the costs incurred in their provision.
} 
which can further be re-arranged to provide an estimating equation for the marginal cost parameters. Under the assumption that unobserved marginal costs $\nu_{j m}$ is distributed bivariate log-normally with mean zero and covariance matrix $\Sigma$ :

$$
\log \left(P_{j m}-\frac{S_{j m}\left(P_{j m}, P_{j^{\prime} m}, X_{m}\right)}{\frac{\partial S_{j m}\left(P_{j m}, P_{j^{\prime} m}, X_{m}\right)}{\partial P_{j m}}}\right)=Z_{j m}^{\prime} \gamma_{j k}+\nu_{j m}
$$

Given estimates of the utility parameters $\left\{\beta_{j k}, \alpha_{k}, \lambda_{k}\right\}$ which generate $S(\cdot)$, we can estimate $\left\{\gamma_{j k}, \Sigma_{k}\right\}$ on the subset of markets where we observe prices.

\subsection{Entry and Exit}

While making pricing decisions, each incumbent provider also makes an exit decision in each period (denoted $d_{l j m t}=0, l$ denotes an individual provider, $j$ the provider type, $m$ the market and $t$ the time-period). Doing so optimally maximizes the discounted sum of future profits give by:

$$
\begin{aligned}
& \max _{d_{l j m t}} \pi_{j m t}-F C_{j m t}+\eta_{l j m t}^{d_{0}} \\
& +I\left\{d_{l j m t}=1\right\}\left(E\left\{\sum_{\tau=t+1}^{T} \delta^{\tau-t}\left(\pi_{j m \tau}-F C_{j m \tau}+\eta_{l j m \tau}^{d}\right) p\left(s_{m \tau} \mid s_{m, \tau-1}, d_{j m \tau-1}=0\right)\right\}+\eta_{l j m t}^{d_{1}}\right)
\end{aligned}
$$

where $F C_{j m t}$ are the fixed costs of operation in market $m$ for provider type $j$ in year $t$, where $\delta$ is the discount factor. The value from exiting in each period is $\pi_{j m t}-F C_{j m t}+\eta_{\text {ljmt }}^{d_{0}}$ and state transitions conditional on staying in the market are given by $p\left(s_{m \tau} \mid s_{m, \tau-1}, d_{j m \tau-1}=1\right)$. Unobserved provider profits in each period are denoted by $\left(\eta_{\text {ljmt }}^{d_{0}}, \eta_{l j m t}^{d_{1}}\right)$ which are distributed i.i.d. Type I Extreme Value. The state vector $s_{m t}$ captures the demand and cost observables, as well as the number of each type of provider. Including fixed costs of operation in the model is important. A maintained assumption throughout is the separability of abortion services and other services in the providers' profit functions. These services exist for hospital and non-specialized providers, and may exist for specialized clinics, who often provide contraceptives and other family planning services 40 Abortion is often subject to opposition, leading to possible picketing, boycotts and physical violence. It is possible that exiting the abortion market to avoid negative externalities on demand for other services increases

\footnotetext{
${ }^{40}$ The Planned Parenthood Federation of America 2006-2007 Annual Report outlines the services distribution.
} 
profit. These gains are captured in the estimates in $F C$ being positive.

Making the assumptions outlined in Rust (1987) of additive separability and along with the conditional independence of $s_{m t}$ and $\eta_{\text {ljmt }}^{d}$, the provider problem can be rewritten via the Bellman equation:

$$
V_{j t}\left(s_{m t}, \eta_{l j m t}^{d}\right)=\max _{d_{l j m t}}\left(v_{j t}\left(s_{m t}, d_{l j m t}\right)+\eta_{l j m t}^{d}\right)
$$

where the choice specific value function takes the form:

$v_{j t}\left(s_{m t}, d_{l j m t}\right)=\pi_{j m t}+\delta \int_{\eta_{t+1}} \int_{s_{m, t+1}} V_{j t+1}\left(s_{m, t+1}, \eta_{l j m, t+1}^{d}\right) p\left(s_{m, t+1} \mid s_{m t}, d_{l j m t}\right) d F\left(\eta_{l j m, t+1}^{d}\right)$,

Given the generalized extreme value (GEV) structure of the error terms, one can substitute a closed form for the expected value of facing the choice set in the future:

$$
\begin{gathered}
\int_{\eta_{t+1}} \int_{s_{m, t+1}} V_{j, t+1}\left(s_{m, t+1}, \eta_{l j m, t+1}^{d}\right) p\left(s_{m, t+1} \mid s_{m t}, d_{l j m t}\right) d F\left(\eta_{l j m, t+1}^{d}\right)= \\
\int_{s_{m, t+1}} \log \left(\sum_{d=0}^{1} e^{v_{j, t+1}\left(s_{m, t+1}\right)}\right) p\left(s_{m, t+1} \mid s_{m t}, d_{l j m t}\right)+\gamma
\end{gathered}
$$

With this substitution, one can re-write a provider's problem as a simple binary decision in each period with the provider deciding to exit $\left(d_{l}=1\right.$, suppressing, market, type, and time subscripts) by comparing the following choice-specific value functions:

$$
\begin{aligned}
& V_{d_{1}}(s)=\pi(s)-F C+\eta_{l}^{d_{1}}+\delta\left(\int \log \left(\sum_{d^{\prime}=0}^{1} e^{V^{\prime}\left(s^{\prime}, d^{\prime}\right)}\right) p\left(s^{\prime} \mid s, d_{l}=1\right)+\gamma\right) \\
& V_{d_{0}}(s)=\pi(s)-F C+\eta_{l}^{d_{0}}
\end{aligned}
$$

where $\gamma$ is Euler's constant. The problem for potential entrants is very similar to that for incumbents outlined above. The only differences are that entering providers pay a different (market, time and provider specific) fixed cost in the entry period and do not provide abortions until the following period. This structures gives rise to potential entrants facing the following two choice-specific value functions when considering whether or not to enter:

$$
\begin{aligned}
& V_{e_{0}}(s)=\eta_{l}^{e_{0}} \\
& V_{e_{1}}(s)=F C E+\eta_{l}^{e_{1}}+\delta\left(\int \log \left(\sum_{d^{\prime}=0}^{1} e^{V^{\prime}\left(s^{\prime}, d^{\prime}\right)}\right) p\left(s^{\prime} \mid s, e_{l}=1\right)+\gamma\right)
\end{aligned}
$$


where $F C E$ captures the fixed costs of entry associated with beginning the provision of abortion services. How FCE varies with supply side regulations is a parameter vector of interest.

\subsubsection{Using Conditional Choice Probabilities}

Under any generalized extreme value (GEV) error distribution there exits an equivalence between the expected value of making a choice in the future and the probability of exit. To see this, note that the probability of exiting is given by:

$$
P\left(d_{l}=0\right)=\frac{e^{V_{d_{0}}(s)}}{e^{V_{d_{1}}(s)}+e^{V_{d_{0}}(s)}} .
$$

Taking the natural log of both sides yields the following:

$$
\log \left(e^{V_{d_{1}}(s)}+e^{V_{d_{0}}(s)}\right)=V_{d_{0}}(s)-\log P_{0}(s)
$$

where $V_{d_{0}}(s)$ is the value from exiting at state $s$. Given the timing outlined above, $V_{d_{0}}(s)=\pi(s)-F C$. Substituting this into (9), the value for incumbents staying in the market relative to exit is given by:

$$
V_{d_{1}}(s)-V_{d_{0}}(s)=\eta_{l}^{d_{1}}-\eta_{l}^{d_{0}}+\delta\left(\int\left(\pi\left(s^{\prime}\right)-F C^{\prime}-\log \left(P_{0}\left(s^{\prime}\right)\right)\right) p\left(s^{\prime} \mid s, d_{l}=1\right)+\gamma\right) .
$$

$P_{0}\left(s^{\prime}\right)$ is the probability of exiting the market conditional on facing tomorrow's statespace $s .^{\prime}$ The only expectation is over transitions to tomorrow's state $s^{\prime}$, and $\eta_{l}^{1}-\eta_{l}^{0}$ is distributed logistic. This substitution follows from assuming exit is an absorbing state in the language of Hotz and Miller (1993).

In a similar fashion, the potential entrants' problem can be rewritten as the following value for entering relative to not entering:

$$
V_{e_{1}}(s)-V_{e_{0}}(s)=F C E+\eta_{l}^{e_{1}}-\eta_{l}^{e_{0}}+\delta\left(\int\left(\pi\left(s^{\prime}\right)+F C^{\prime}-\log \left(P_{0}\left(s^{\prime}\right)\right)\right) p\left(s^{\prime} \mid s, e_{l}=1\right)+\gamma\right)
$$




\subsubsection{Formulating the Likelihood}

This approach allows us to express an individual providers' probability of entry and exit as a function of elements which can be estimated separately $\left(\hat{\pi}, \hat{P}_{0}, \hat{p}\right)$; however we observe the total number of providers of each type operating in the market across time. Thus the probabilities of entry and exit need to be combined to generate the probability of observing the number of providers of each type $j$ in market $m, N_{j m t}$.

The likelihood of observing $N_{j m t}$ is given by a logit mixture distribution, which is limited in each particular market by either the number of potential entrants or the number of incumbent providers, depending on the prior state of the market. The probabilities of entry and staying in the market are identified by variation in markets with the same current number of providers and different number of providers in the preceding and proceeding periods, respectively. The log-likelihood for an observed number of providers $N_{t}$ (suppressing market- $m$ and type- $j$ subscripts) takes the following form, where $\bar{M}=\max \left\{N_{t}, N_{t-1}\right\}$ and $\underline{M}=\min \left\{N_{t}, N_{t-1}\right\}$ :

$$
\sum_{n=0}^{M^{*}}\left(\begin{array}{c}
N_{t-1} \\
\underline{M}-n
\end{array}\right)\left(\begin{array}{c}
N_{p} \\
M-\underline{M}+n
\end{array}\right)\left(1-P_{d_{1}}\right)^{\bar{M}-\underline{M}+n} P_{d_{1}}^{\underline{M}-n}\left(1-P_{e_{1}}\right)^{N_{p}-\bar{M}-\underline{M}-n} P_{e_{1}}^{\bar{M}-\underline{M}+n} .
$$

$N_{p}$ is the number of potential entrants, $P_{d_{1}}$ and $P_{e_{1}}$ are respectively the probabilities of an incumbent staying and an entrant entering, and $n$ is the (unobserved) number of entering providers in time $t$. The limit $M^{*}$ (and thus how many terms enter the likelihood contribution) takes on four different values depending on whether the market is in one of four states:

1. the number of providers today and yesterday is the same and less than the number of potential entrants $\left(M^{*}=N_{t-1}\right)$,

2. the number is the same and greater than the number of potential entrants $\left(M^{*}=N_{p}\right)$

3. the number of providers today is greater than yesterday $M^{*}=\min \left\{N_{t-1}, N_{p}-\right.$ $\left.\left(N_{t}-N_{t-1}\right)\right\}$, and

4. the number of providers yesterday is greater than today, $M^{*}=\min \left\{N_{t-1}, N_{p}-\right.$ $\left.\left(N_{t-1}-N_{t}\right)\right\}$. 
The likelihood takes this complex form because the number of entrants can be greater than one ${ }^{41}$ Expressions for $P_{d_{1}}$ and $P_{e_{1}}$ can be taken from the structural model above, or these probabilities can be parameterized solely as a function of observables (e.g. with no reference to beliefs and expectations over future profitability). We use both approaches in the estimation outlined below.

\subsubsection{Expectations and Transitions}

By estimating reduced-form probabilities of entry and exit, one can compute the transition probabilities $p\left(N_{j m t} \mid N_{j m, t-1}\right)$ for the number of providers of each type $j$, and one-step ahead probabilities of exit. We assume providers follow this expectation when forecasting who will be operating in the market next period. Because we only require one-step ahead probabilities to estimate the dynamic model, we need not specify expectations past one-period ahead. Whatever the expectations process beyond one period, the reduced form $P_{0}\left(s^{\prime}\right)$ completely measures the perceived future profitability of staying in the market. Here, we assume the regulatory environment faced at time $t, R_{t}$, is known one-period in advance. This assumption is consistent with the lagged nature of regulation, and the active efforts by groups such as NARAL to alert the public to proposed legislation and regulation 42 Transitions for the remainder of the state-space (which are all continuous) are modeled as AR-1 process, with a separate mean and standard deviation. Finally, we also assume that the fixed costs of entry and operation are independent of the state transitions from $s$ to $s^{\prime}$, allowing them to be factored out of the integrals in (13) and (14).

\subsubsection{Forward Simulation}

Some markets contain many providers; even capping the number of hospital providers at one hundred leads to just over 29 million different states. Rather than keeping track

\footnotetext{
${ }^{41}$ This formulation of the likelihood, although complicated can be estimated fairly easily given the case-structure. Many studies of industry dynamics focus on the number of competing providers being quite small, generally less than five. This likelihood formulation on the other hand, along with some restriction on the pool of entrants, can allow a general number of providers.

${ }^{42}$ Viewing regulations as part of the state space, what is required for this formulation to correctly measure profits is that the regulation evolutions, say $q\left(R^{\prime} \mid R\right)$ be conditionally independent of the private information profits $\eta$. So the extent to which individuals forecast ahead more than one period the regulatory environment in the future is accounted for in the reduced form probability of exiting in the next period. In estimating these reduced forms I include the regulations as well as the entire state space.
} 
of that number of probabilities for use as weights in calculating the integrals in (13) and (14), I follow a different method for calculating future values presented in Bajari, Benkard and Levin (2007), and used in Bishop (2012). Since we have reduced forms on the probability of entry and exit for incumbent providers and potential entrants, I simulate the number of providers operating in the market tomorrow from these probabilities, solve the static price-setting game, and take an average of the resulting one-step ahead profitability of being in tomorrows market:

$$
\int\left(\pi\left(s^{\prime}\right)+F C^{\prime}-\log \left(P_{0}\left(s^{\prime}\right)\right)\right) p\left(s^{\prime} \mid s, d=1\right) \approx \frac{1}{N_{s}} \sum_{\operatorname{sim}_{s}=1}^{N_{s}} \pi\left(\operatorname{sim}_{s}\right)+F C^{\prime}-\log \left(P_{0}\left(\operatorname{sim}_{s}\right)\right) .
$$

The simulated states $\operatorname{sim}_{s}$ is a draw on the number of firms and the continuous elements of the state vector (population, income, demographics etc), given today's value for each. It probabilistically include the competitive environments which are most likely to be seen next period and as the number of simulations increases, the simulated sum will converge to the sum over all the possible states. Bajari, Benkard and Levin (2007) proposed this simulation method to calculate future values for many periods into the future; with an absorbing state and logistic errors, one need only to simulate the next period future value term.

\subsection{State Space and Equilibrium}

Equilibrium strategies consist of pricing, entry, or exit choices. Following the work of Bajari, Benkard and Levin (2007), I assume providers play Markov-perfect pure strategies, which are symmetric and anonymous. Formally the strategy $\sigma_{l}$ for a provider is a function $\sigma_{l}: S \times E \mapsto\left(P_{l}, d_{l}, e_{l}\right)$, where $S$ is the current state, $\mathrm{E}$ is the vector of current unobservables (demand, marginl costs and profits), and $\left(P_{l}, d_{l}, e_{l}\right)$ are the quantity, entry and exit decisions in the current period. Doraszelski and Satterthwaite (2010) show private information shocks ( $\eta$ here) are necessary to ensure the existence of a pure strategy MPE in a dynamic model of entry and exit with investment. Aguirregabiria and Mira (2007) set forth the assumptions which identify the model in the presence of multiple equilibria, which do exist even in simple models

as shown in Doraszelski and Satterthwaite (2010). I maintain the assumption that the same equilibrium is played in all markets.

The state space discussed throughout includes the number of providers of each 
type within the market, and a set of observable market level characteristics including abortion regulations, total population, density, income, and the variables measuring the religious characteristics of the population. Also included in the state space are the state in which the provider operates and the calendar year. The observable market characteristics are especially relevant given the large variation in demand for abortion across markets.

Finally the timing of decisions in the model follows Doraszelski and Satterthwaite (2010) and Ryan (2012) fairly closely.

- Each incumbent and potential entrant receive a set of private information draws, $\eta$. Incumbents see their (common) marginal costs $\left(\nu_{j m}\right)$. Providers observe the current number of providers of the three types operating in the market. Incumbents and entrants make simultaneous choices over entry and exit.

- Providers engage in simultaneous price setting.

- Incumbent providers exiting leave the market, potential entrants entering join the market.

- The state vector adjusts to reflect any (net) differences in the number of competitors from entry and exit.

Providers leaving the market still provider services in the current period and exit only afterwards, while entering providers sit out the current period and the begin operations. Since the unobserved marginal costs are independent over time providers do not attempt to learn about other types' costs from one period to the next.

\subsection{Including Unobserved Heterogeneity}

In order to the relax the assumption of independence over time in all of the unobservables, I incorporate unobserved heterogeneity into the model. Market-level abortion demand may be fluctuating over time in ways not captured by our observables. Similarly the costs of entry and operation may be changing differentially across markets, especially for cities which saw dramatic increases in abortion provision over the period (e.g. Miami).

Heckman and Singer (1984) proposed approximating a continuous unobserved distribution by using a discrete approximation. I adopt the work of Arcidiacono and 
Miller (2011) and Arcidiacono and Jones (2003) by using their adaptations of the Expected-Maximization (EM) algorithm. Here I assume that each market belongs to one of $K$ types in each period, while $K$ is known, the type of each market in each period $k(t)$ is unobserved to the econometrician. This form of unobserved heterogeneity can vary over time following a Markov chain. In this a setting, the unconditional likelihood for observing a sequence of providers in a market over time $N_{j m}$, takes the following form:

$$
\begin{aligned}
& l\left(N_{j m} \mid \mathbf{X}_{m}, \theta_{j}, \rho, P_{0}, p, \pi\right)=\sum_{k(1)} \sum_{k(2)} \ldots \sum_{k(T)} \rho_{k(1)} f\left(N_{j m n 1} \mid \mathbf{X}_{m 1}, \theta_{j}, k, \rho, P_{0}(k), p(k), \pi(k)\right) \\
& \times \prod_{t=2}^{T} \rho_{k(t-1), k(t)} f\left(N_{j m t} \mid, \mathbf{X}_{m t}, k(t), \theta_{j}, \rho, P_{0}(k(t)), p(k(t)), \pi(k(t))\right)
\end{aligned}
$$

where $\theta_{j}$ are the structural (or reduced-form) parameters governing entry and exit probabilities, and $\mathbf{X}_{m}$ is the entire state-space of observables. Here $\rho_{k}(1)$ is the initial (period 1) probability of a market being type $k$. The transition probabilities on the unobserved state $k$ are given by: $\rho_{k(t-1), k(t)}$, and $\rho$ is the vector of all initial and transition probabilities. $P_{0}$ denotes the conditional choice probability reduced forms, $p$ is the transition function for the state variables, and $\pi$ are the per-period profit functions. The parameters of $\left(P_{0}, p, \pi\right)$ can each depend on the unobserved state.

The log-likelihood for time transitioning unobserved heterogeneity takes the following form:

$$
\log \left(\ell_{j}\right)=\sum_{m=1}^{865} \log \left(l\left(N_{j m} \mid \mathbf{X}_{m}, \theta_{j}, \rho, P_{0}, p, \pi\right)\right)
$$

To estimate such a likelihood, I adopt the methods put forward in Arcidiacono and Miller (2011) and rather than directly maximize (18), I instead iteratively maximize the expected log likelihood function. This maximization takes the following form:

$$
\left.\max _{\theta_{j}} \quad \sum_{n=1}^{N} \sum_{k=1}^{K} \sum_{t=1}^{T} q_{k m t}^{(i)} \log \left(f\left(N_{j m t} \mid \mathbf{X}_{m}, \theta_{j}, \rho^{(i)}, \hat{P}_{0}^{(i-1)}(k), \hat{p}^{(i-1)}(k), \hat{\pi}^{(i-1)}(k)\right)\right)\right)
$$

where $i$ is the iteration and $q_{k m t}^{(i)}$ is the probability of market $m$ being in unobserved state $k$ at time $t$, conditional on the last iteration parameter estimates, all the data from the market $\mathbf{X}_{m}$, past and future, and using information from the other types of providers (note $q_{k m t}^{(i)}$ is not-subscripted b y $j$ ). 
One can proceed by simultaneously estimating all the $\theta_{j}$ along with parameters of $P_{0}, p$, and $\pi$, or (as we do here) by iterating between estimating the parameters of $\theta_{j}$ and $\left(P_{0}, p, \pi\right)$; in either case the maximization step is followed by recalculating $\left(q_{k m t}^{(i)}, \rho\right)+43$

\subsubsection{Two-Step Method}

We adapt a version of the two-step method for calculating $q_{k m t}$ outlined in Arcidiacono and Miller (2011). This approach allows us to forward simulate the future value terms in equations (13) and (14) only one time, following the convergence of $q_{k m t}$. Our estimation approach repeats the following steps until convergence, given an initial $q_{k m t}^{(i)}$ :

- (1a) Estimate demand parameters which can vary with unobserved heterogeneity $\left\{\beta_{j k}, \alpha_{k}, \lambda_{k}\right\}^{(i)}$ using weighted two-stage least squares and $q_{k m t}^{(i)}$ as weights.

- (1b) Estimate marginal cost parameters from Equation (4), $\left\{\gamma_{j}, \Sigma_{k}\right\}^{(i)}$ using weighted least-squares.

Next we:

- (2a) Maximize the reduced-form weighted likelihood of $N_{j}$ in (15), once for each $j$, estimating $\theta_{j k}^{(i)}$.

- (2b) Calculate $q_{k m t}^{(i+1)}$ and $\rho^{(i)}$ using the state-conditional likelihoods of $N_{j k}$ when only observing $N_{j}$, and including $\phi\left(\frac{\log \left(M C_{j}\right)-Z_{j}^{\prime} \gamma_{j}}{\sigma_{j k}}\right)$ when we also observe prices.

- (2c) Taking the sequence of state-conditional likelihoods from (2b) over $t=$ $2, \ldots, T$ as given, estimate the initial conditions $\rho_{1}^{(i)}$ as weights on the conditional sequences 44

Following convergence in $q_{k m t}$, we then simulate the future value terms in (13) and (14) using estimates of $\left(\hat{P}_{0}, \hat{p}, \hat{\pi}\right)$. With these simulated terms in hand we can estimate $\left(F C_{j k}, F C E_{j k}\right)$ using weighted maximum likelihood with $q_{k m t}^{(i+1)}$ as weights.

\footnotetext{
${ }^{43}$ See Appendix B.

${ }^{44}$ We use the pre-1973 early legalization regimes as predetermined shifters to solve the initial conditions problem.
} 


\section{$5 \quad$ Estimation and Results}

\subsection{Recovering First-Stage Parameters}

Estimates from the demand model outlined in Equation 1 are presented in Table 8 . The first two columns show that the price elasticities are under-estimated via OLS, e.g. prices are inversely correlated with market shares in the raw data. Using the average price among NHNCs in the same state-year but in other metro areas as an instrument nearly doubles the price elasticity of abortion demand, placing it in line with the literature's prior estimates ${ }^{45}$ The instrument for price is strong, and reflect unobserved state-level factors such as input price changes ${ }^{46}$ The coefficients in $\beta_{j}$ are suppressed for ease of exposition, but the effects of demand aimed policies on clinics are listed in the table ${ }^{47}$ In line with prior studies we find waiting period laws caused significant reductions the abortion demand. The first and second columns assume a logit demand structure, relaxing that structure in column three shows that there is a significant correlation between the unobservables affecting all the abortion choices. We also find that parental consent laws have a sizable impact on (clinic) demand in addition to waiting periods. Finally in the fourth column we include the weights from the dynamic estimation and allow some parameters to vary with the unobserved heterogeneity, revealing that the price elasticities are slightly smaller when controlling for the correlation in the unobservables over time. This could reflect differential degrees of price discounting or willingness to substitute toward other options across markets.

\footnotetext{
${ }^{45}$ The response of abortion demand to prices was first established in Medoff (1988), with elasticity estimates near 1.

${ }^{46}$ The excluded F-test for price instruments is 33.7, and for the share instruments it is 4.3.

${ }^{47}$ Column four has 306 demand parameters: three $\alpha_{k}$, three $\lambda_{k}$, six $\beta_{0 k}$, and 98 demand parameters for each provider type $j$. The variables included in $X_{m t}$ are: five supply-aimed regulations (second trimester and agreements with hospital requirements, license laws, physical administrative requirements and restrictions on which physicians can perform abortions), and demand regulations (consent, notification, waiting period and funding); a fifth order polynomial in population, and indicator for population greater than two million, population fraction female of reproductive age (15-44), overall and black, population density, per capita income, and the total number of religious adherents, Catholics and Southern Baptists; also included are indicators for being a the only clinic, NHNC or hospital provider and second-order polynomials in the number of each type of provider.
} 


\subsection{Recovering Marginal Costs}

Estimates from the marginal cost regression are presented in Table 9. Results are presented only for non-hospital providers, and for each unobserved state. Restrictions on which physicians can provide abortions significantly increase the marginal costs of provision for clinics, which is expected since clinics are much more likely to employ other types of health care providers (e.g. nurse practitioners). The law also lowers the marginal costs of provision for NHNC's, a result likely driven by increased concentration of services at NHNC's under this legal restriction. ${ }^{48}$ Requirements that second trimester abortions be performed in free-standing surgical center moves these high-cost services out of NHNC's, and so lowers their marginal costs. Abortion licenses also raised the marginal costs for both type of providers. Finally, physical and administrative requirements given so much attention in press, have no significant positive impact on marginal cost, though there magnitude for NHNC's is non-trivial.

The second panel of Table 9 shows estimates for $\gamma_{j k}$, the impact of marginal cost shifters. These shifters come from state and metro-area level information on health care markets: the number of physicians and hospitals per capita in the state and the number of employees working in health services in the metro area. Signs are mixed, more hospitals per capital raises marginal costs for clinics but lower then for NHNC's, physicians do the opposite, and areas with more health services employees see lower costs for NHNC's, but at a declining rate. These estimates reflect the ambiguity of effects: a larger health care sector both lowers search costs and may increase specialization and wages among health care workers. These estimates are especially useful for projecting costs in areas where do not observe prices. Despite most coefficients being very similar across columns, the unobserved heterogeneity does play an important role: the final row shows mean marginal costs are significantly different across the three states.

\subsection{Recovering Entry and Exit Costs}

Estimates of the fixed enter and operation costs are presented in Table 10. The estimates reveal that the only significant impacts of supply-side regulation are observed among NHNC's. Licensing and restrictions on which physicians can perform abor-

\footnotetext{
${ }^{48}$ For simplicity the model assumes constant marginal costs with respect to the number of abortions provided.
} 
tions reduce the profitability from operation and entry respectively. Coefficients are in millions of 2005 dollars, so the imposing of a physician restriction raises entry costs by roughly $\$ 650,000$. Other observables are included in the entry and operation costs to capture setup costs as well as organized efforts against abortion providers. Operating in a larger health-care market increased profitability for NHNC's, and increased the profitability of clinic entry in ways not captured by the profit estimates. These may reflect more complex elements of the medical market such as referral networks. Poorer metro-areas were more profitable to enter, likely because setup costs are lower (the increased demand for abortion among poor women is already captured in the future value calculations). Finally, Catholics and Southern Baptists are the two largest religious groups with a history of organizing and protesting abortion providers. Their population along with estimates of the total number of religious adherents in the metro area included. These two variables are correlated making interpretation less straightforward. An increase in the number of adhering Catholics or Southern Baptists (so both variables increase) on net decreases the profitability of operating both Clinics and NHNC's and increases the costs of entry among Clinics. The final set of estimates in the table, the unobserved heterogeneity and constant terms reveal that abortion is largely unprofitable. Already included in the regression with these coefficients is the current and discounted life-time profit of operating a provider. Thus the positive constant terms capture the dimensions of profit or utility left out of our estimates. These reflect spillovers in the profit function which are otherwise not modeled (e.g. interactions between providing abortions and other services such as contraceptives, or providers utility offering the service). The magnitude of these spillovers vary greatly with the unobserved heterogeneity a well (e.g. when $k=2$ they are near zero for NHNC's). The constants and unobserved heterogeneity also reveal large entry costs, which means regulation can have important long-term consequences, since on average few providers will enter following an exit.

\subsection{Model Fit}

With the three stages of the model estimated we can simulate the number of providers, price competition and the resulting number of abortions observed in equilibrium. Figure 3 presents the time profile on the number of providers. The model captures the overall trend, while missing the abrupt decline, mainly among NHNC's, around 1991. These model predictions come from pegging the number of firms to the observed 
number in 1973, and simulating entry using the structural profit functions outlined above for clinics and NHNC's (these include the fixed costs and future value terms which take into account equilibrium profit from simulating Bertrand-Nash competition). Hospital behavior is simulated only using the reduced form estimates for entry and exit. Conditional on the simulated number of providers and unobserved state, Bertrand-Nash price competition can simulated by iterating on the set of non-linear equations which define both prices and market shares as functions solely of market shares. Here we exploit the fact that NHNC and clinic prices can be expressed as a non-linear function of market shares, $\left(\alpha_{k}, \lambda_{k}\right)$, and marginal costs. The optimal prices can be expressed as:

$$
\begin{aligned}
P_{\text {Clinic }} & =\frac{-1}{\alpha_{k} S_{\text {Clinic }}-\alpha_{k} / \lambda_{k}-\alpha_{k}\left(\lambda_{k}-1\right) / \lambda_{k} S_{\text {Clinic }, g}}+\hat{M} C_{k, \text { Clinic }} \\
P_{N H N C} & =\frac{-1}{\alpha_{k} S_{N H N C}-\alpha_{k} / \lambda_{k}-\alpha_{k}\left(\lambda_{k}-1\right) / \lambda_{k} S_{N H N C, g}}+\hat{M} C_{k, N H N C},
\end{aligned}
$$

where $S_{j}$ refers to provider type- $j$ 's market share, and $S_{j, g}$ refers to provider type$j$ 's share of abortions (the within nest share). Substituting these equations in the demand system in Equation (2) allows one to solve for a counter-factual equilibria in a given market-year (including those where we do not observe prices) by solving the non-linear system of share equations 49

Figures 4 presents the overall simulated market shares, and for the three providers. While the overall fit is close to the data, the model predicts larger shares among NHNC's and smaller shares among Clinics than we see in the data. Hospital shares are captured quite closely. In Figure 5 we present the same measures but focusing on only the larges $10 \%$ of markets historically. These markets accounted for more than $96 \%$ of abortions over the time period. As can be seen the gap between the data and clinic shares noticeably diminishes, suggesting that the model over predicts NHNC's shares in markets with very few abortions, an important point below when simulations focus on the total numbers of abortions under different policy regimes.

\footnotetext{
${ }^{49}$ We solve the system by beginning at the observed shares, iterating on the equations defined by (2), but stepping away form the old shares with small step-sizes at each iteration, which ensures we stay at a price equilibrium near the observed equilibrium.
} 


\section{Simulations}

Given plausible estimates of the model parameters and fitness we perform two sets of counter-factual policy simulations to understand both the drivers behind the decline in abortion from 1991 to 2005, and the role of tight supply-side regulation on the evolution of the U.S. abortion market.

First we simulate freezing observables at their observed 1991 levels across three groups: demand characteristics, demand regulations and supply regulations. Secondly we simulate unannounced repeal of the demand and supply regulations in 1991, simulating the markets forward until 2005 and examining the subsequent declines. The the second counter-factual takes the regime from one of the most highly regulated states in the U.S., Utah, and simulates the national market under the time-path of Utah regulations beginning in 1976

Table 11 presents results for a number of counter-factual declines in the number of abortions and providers, both overall and split by provider types. The first row shows that the model baseline does a good job of predicting the overall decline in providers and abortions: the data showed a $21 \%$ decline in abortions and a $33 \%$ decline in the number of providers from 1991 to 2005. The second row examines how much of the decline can be attributed to changes in the demographics away from higher demand for abortions. Only $8 \%$ (1.6 points of the 21.2 point decline) of the decline was due to shifts in population demographics (e.g. income and the population age distribution). This simulation may miss the unobserved factors which are not fully captured here most importantly, increased use of birth control technologies, which influence demand in the model via linear trends at the region level. In contrast demand regulation changes between 1991 and 2005 accounted for more than 15\% of the decline (3.2 points of the 21.2 point decline), with increases in the supply regulation over the period contributing nothing to the observed declines in abortion. It's also the case that the most relevant supply regulations, licensing and physician restrictions, were largely in place before 1991, so freezing supply regulations has no noticeable impact on the distribution of providers either. The final two rows in Table

\footnotetext{
${ }^{50}$ In terms of counting regulations, North Carolina had the most regulation-years, but also provided public funding for much of the sample period. Utah had the second most regulation-years of any state. Results are similar when imposing the Utah regime in 1973, but allowing markets to become populated over the first 3 years allows the number of providers to be much closer in the model and the data in the initial simulation period.
} 
11 examine counter-factual declines if the set of supply and demand restrictions were removed in 1991 respectively 51 Repeal of supply regulations has a large impact on the network of abortion providers, reducing the overall decline in providers by twothirds, primarily among clinics and NHNC's. This is attributable to the decreased entry barriers among NHNCs, reductions in marginal costs among clinics, as well as direct effects the number of providers has on demand (e.g. an increase in providers lowers travel costs and so increases demand). This entry would have resulted in more procedures performed, and the decline would have been $24 \%$ smaller (16.2 points of the 21.2 point decline). Repealing demand regulations would also increse the number of abortions by a similar magnitude, but with very little change in the network of providers. Table 12 shows how changes in repeal affect access over time as measured by metro-areas without any abortion provider. The repeal of supply regulation and expansion of entry among non-hospital providers does translate into entry in areas with no providers: by 2005 the number of areas with no provider was reduced by $6 \%$.

The second counter-factual simulates the Utah abortion-law regime for the entire nation, and results are presented in Table 13 . The first panel shows the percentage changes in abortions under the tight-regulation regime, the second panel the change in providers 52 The initial results are as one would expect, making entry more costly and restricting demand slightly reduced the overall number of abortions in 1976 and 1991, but the period from 1991 to 2005 shows a surprising result: net abortions increased. Indeed the number of abortions increased so much over this part of the sample period that the net effect of tight abortion regulation on abortions was actually positive $(0.25 \%)$. The results flow from an intereaction between the supply-side, the demand side and regulations. Imposing Utah regulations dramatically reduced the number of NHNC's (more than cutting their number in half by 2005). In response clinics entered the market in large numbers later in the sample period, with so few higher priced competitors in the market, entry among abortion clinics is more profitable. This entry translates into significantly more abortions mainly because clinics offer lower-priced services and generate indirect increases in demand. Even suppressing the Clinic response, say because one believes non-profits would not move to fill in

\footnotetext{
${ }^{51}$ Public funding is not changed in these simulations; its' impacton demand was negligible.

${ }^{52} \mathrm{Utah}$ had both a physician restriction and licensing law in place for most of the sample period; in 1998 it added restrictions that non-hospital providers have both agreements and locate within a certain travel distance from nearby hospitals. They also maintained a parental notice law throughout the sample period and added a waiting period law in the early 1990s.
} 
markets when NHNC's exit, hospital provision and entry still compensate to a lesser degree for the exit of NHNCs. Thus the simulations reveal that tightly regulating abortion providers in the presence of available substitutes will not significantly reduce the number of procedures. The final panel of Table 13 shows that the Utah regime does decrease access, increasing the number of markets with no providers by more than $10 \%$.

\section{Conclusion}

How do supply-aimed abortion regulations influence the provision of services in U.S.? This paper argues that the interactions of providers prove to be consequential in understanding to what extent state policies have been responsible for the recent declines in abortion observed in the United States. Estimating a dynamic model of imperfect competition among providers in the U.S. reveals that state regulations impact demand, marginal and fixed costs in the market, with the most relevant supply-effects observed among non-hospital non-clinic abortion providers. Entry costs in this market are high, likely reflecting the controversial nature of the services and subsequent interactions between providing abortions and providers other service offerings.

We find that although supply-aimed abortion regulations played an important role in generating the observed market structure, there is no evidence that their more recent imposition has changed the market. Rather pre-existing trends in the decline of provision and abortion at the state-level is correlated with the introduction of these more recent measures, so that policy effects are small and insignificant when conditioning on these trends. In contrast demand-aimed restrictions, waiting periods and parental consent laws, were the single most important observable factor in explaining recent declines in the number of abortions.

Counterfactual simulations reveal important unintended consequences for regulations targeting the supply-side of the abortion market. If a strict set of regulations were put in place early in the history of nationalized legal abortion in the U.S., simulations indicate the result would be a net increase in the number of abortions observed in equilibrium. This finding arises mainly because of the interaction between competitors on the supply-side of the market: a strategic response of increased entry among clinics and substitution toward the increased number of hospital providers. 


\section{References}

Aguirregabiria, Victor and Pedro Mira, "Sequential Estimation of Dynamic Discrete Games," Econometrica, 01 2007, 75 (1), 1-53.

Arcidiacono, Peter and John Bailey Jones, "Finite Mixture Distributions, Sequential Likelihood and the EM Algorithm," Econometrica, 05 2003, 71 (3), 933946.

- and Robert A Miller, "Conditional Choice Probability Estimation of Dynamic Discrete Choice Models with Unobserved Heterogeneity," Econometrica, Nov 2011, $7(6), 1823-1868$.

Bajari, Patrick, C. Lanier Benkard, and Jonathan Levin, "Estimating Dynamic Models of Imperfect Competition," Econometrica, 09 2007, 75 (5), 13311370.

Berry, Steven T., "Estimating Discrete-Choice Models of Product Differentiation," RAND Journal of Economics, Summer 1994, 25 (2), 242-262.

Bishop, Kelly, "A Dynamic Model of Location Choice and Hedonic Valuation," Working Paper, Washington University in St. Louis 2012.

Bitler, Marianne and Madeline Zavodny, "The effect of abortion restrictions on the timing of abortions," Journal of Health Economics, November 2001, 20 (6), 1011-1032.

Blank, Rebecca M., Christine C. George, and Rebecca A. London, "State abortion rates the impact of policies, providers, politics, demographics, and economic environment," Journal of Health Economics, October 1996, 15 (5), 513-553.

Collard-Wexler, Allan, "Demand Fluctuations in the Ready-Mix Concrete Industry," Econometrica, 05 2013, 81 (3), 1003-1037.

Doraszelski, Ulrich and Mark Satterthwaite, "Computable Markov-Perfect Industry Dynamics," The RAND Journal of Economics, May 2010, 41 (2), 215-243.

Ericson, Richard and Ariel Pakes, "Markov-Perfect Industry Dynamics: A Framework for Empirical Work," Review of Economic Studies, January 1995, 62 (1), 53-82. 
Haas-Wilson, Deborah, "The impact of state abortion restrictions on minors' demand for abortions," Journal of Human Resources, 1996, 31 (1), 140-158.

_ and Kristen Lindberg, "Regulation and the Optimal Size and Type of Abortion Provider," Applied Economics, April 1999, 31 (4), 409-15.

Heckman, J and B Singer, "The Identifiability of the Proportional Hazard Model," Review of Economic Studies, April 1984, 51 (2), 231-41.

Henshaw, S.K. and J. Van Vort, "Abortion Services in the United States, 1991 and 1992," Family Planning Perspectives, 1994, 26 (3), 100-112.

- and L.B. Finer, "The Accessibility of Abortion Services In the United Staes, 2001," Perspectives on Sexual and Reproductive Health, 2003, 35 (1), 16.

_, J.D. Forrest, and E. Baine, "Abortion Services In the United States, 1981 and 1982," Family Planning Perspectives, 1984, 16 (3), 119.

Hotz, V Joseph and Robert A Miller, "Conditional Choice Probabilities and the Estimation of Dynamic Models," Review of Economic Studies, July 1993, 60 (3), 497-529.

Kane, Thomas J and Douglas Staiger, "Teen Motherhood and Abortion Access," The Quarterly Journal of Economics, May 1996, 111 (2), 467-506.

Levine, Phillip B., "Parental involvement laws and fertility behavior," Journal of Health Economics, September 2003, 22 (5), 861-878.

_, Amy B. Trainor, and David J. Zimmerman, "The effect of Medicaid abortion funding restrictions on abortions, pregnancies and births," Journal of Health Economics, October 1996, 15 (5), 555-578.

Medoff, Marshall, "Price, Restrictions and Abortion Demand," Journal of Family and Economic Issues, December 2007, 28 (4), 583-599.

Medoff, Marshall H, "An Economic Analysis of the Demand for Abortions," Economic Inquiry, April 1988, 26 (2), 353-59.

Nevo, Aviv, "Measuring Market Power in the Ready-to-Eat Cereal Industry," Econometrica, March 2001, 69 (2), 307-42. 
Rust, John, "Optimal Replacement of GMC Bus Engines: An Empirical Model of Harold Zurcher," Econometrica, September 1987, 55 (5), 999-1033.

Ryan, Stephen P., "The Costs of Environmental Regulation in a Concentrated Industry," Econometrica, 05 2012, 80 (3), 1019-1061.

Santelli, John S. and Andrea J. Melnikas, "Teen Fertility in Transition: Recent and Historic Trends in the United States," Annual Review of Public Health, January 2010, 31 (1), 371-83. 


\section{Appendix A: Prices}

As outlined, the price observed is the mean of 10-week procedures with local anesthesia at the county level. This mean includes price from Clinics and NHNC providers. I assume this mean arises from a mixture two prices, a high and low, or non-clinic and clinic respectively, in each market. So within each market the observed mean can be expressed as:

$$
\mu_{o b s}=\frac{1}{N_{r}} \sum_{N_{r}}\left(N_{n h n c} p_{n h n c}+N_{c} p_{c}\right)
$$

where $N_{r}$ is the number of respondents in the market, $N_{c}$ and $N_{n h n c}$ is the number of providers in the market who are clinics and non-clinics, $p_{c}$ is the clinic price and $p_{n h n c}$ is the non-clinic price. What allows solving for the two prices $\left(p_{n h n c}, p_{c}\right)$ is that fact that I also observe the standard deviation of prices within the county. This can be rewritten as:

$$
\sigma_{o b s}^{2}=\frac{1}{N_{r}} \sum_{N_{r}} N_{n h n c}\left(p_{n h n c}-\mu_{o b s}\right)^{2}+N_{c}\left(p_{c}-\mu_{o b s}\right)^{2}
$$

by simply rearranging the sum and substituting in the two prices. Taking from the counts of providers the number of NHNC and clinics within each market, along with the reported number of providers who responded to the pricing survey, I observe everything except the two prices. These two equations form a non-linear system with two unknowns which can be solved with a non-linear solving routine in most software applications.

\section{Appendix B: Weights for Iterative Maximization}

To build $q_{k m t}^{(i)}$, first define the joint probability of a sequence through time and single a realization of the unobserved variable at a point in time. Suppressing the market-level subscript $m$ this is the joint probability that (1) the sequence $N_{j}$ of providers (of type $j$ ) occurs across all $t$ and that (2) state $k$ occurs at exactly time $t$ in market $m$, we label this $L_{j k t}\left(N_{j} \mid \mathbf{X}, \theta_{j}, \rho, P_{0}, p, \pi\right)$. Firstly, denote $f_{j k t}=$ $f\left(N_{j t} \mid X, k(t), \theta_{j}, \rho^{(i)}, P_{0}^{(i-1)}(k), p^{(i-1)}(k), \pi^{(i-1)}(k)\right)$. We can then write down an ex- 
pression for $L_{j k t}\left(N_{j} \mid \mathbf{X}, \theta_{j}, \rho, P_{0}, p, \pi\right)$ of the following form:

$$
\begin{gathered}
L_{j k t}\left(N_{j} \mid \mathbf{X}, \theta_{j}, \rho, P_{0}, p, \pi\right)=\sum_{k(1)} \ldots \sum_{k(t-1)} \sum_{k(t+1)} \ldots \sum_{k(T)} \rho_{k(1)} f_{j, k(1), 1}\left(\prod_{r=2, r \neq t, r \neq t+1} \rho_{k(r-1), k(r)} f_{j, k(r), r}\right) \\
\ldots \cdot \rho_{k(t-1), k} f_{j k t} \rho_{k, k(t+1)} f_{j, k(t+1), t+1}
\end{gathered}
$$

This expression is a function of $\left(N_{j}, k(t)\right)$, and records all the different paths the unobserved state could have taken through time while still being in state $k$ at time $t$. This expression exploits information present in the data from all periods to express the joint probability of $\left(N_{j}, k(t)\right)$. Although summing over possible paths is tedious, Arcidiacono and Miller (2011) point out it is a known function of known objects: the conditional likelihoods and the transition probabilities, and is in that sense straightforward. Permanent unobserved heterogeneity in this setting is a subset of these paths: namely the path in which the same $k$ occurs in every period.

Given this conditional-on- $k(t)$ probability, we can integrate out $k(t)$ in a given time period, and write down the conditional probability of being type- $k$ in time period $t$ :

$$
q_{k t}=\frac{L_{k t}}{L_{t}}=\frac{\prod_{j} L_{j k t}}{\sum_{k} \prod_{j} L_{j k t}}
$$

where independence of the unobserved profit across provider types $j$ means we can multiply the contributions of each type.

The final pieces of the algorithm are how to update $\rho$. Explained in greater detail in Arcidiacono and Miller (2011), the updating for transitions follows from the definition:

$$
\rho_{k l}=\operatorname{Pr}\{l \mid k\}=\frac{E_{n}\left[q_{l t \mid k} q_{k t}\right]}{E_{n}\left[q_{k t}\right]}
$$

where the expectation is taken over the entire sample, and $q_{l t \mid k}$ is the probability of being in state $l$ at time $t$ conditional on the data and being in state $k$ at time $t-1$. In the iterative updating we close the algorithm with:

$$
\rho_{l k}^{(i+1)}=\frac{\sum_{n} \sum_{t=2} q_{l t \mid k}^{(i)} q_{k t}^{(i)}}{\sum_{n} \sum_{t=2} q_{k t}^{(i)}} \text { and } \pi_{k}^{(i)}=\frac{1}{N} \sum_{n} q_{k 1}^{(i)} .
$$


Figure 1: Regulation Changes

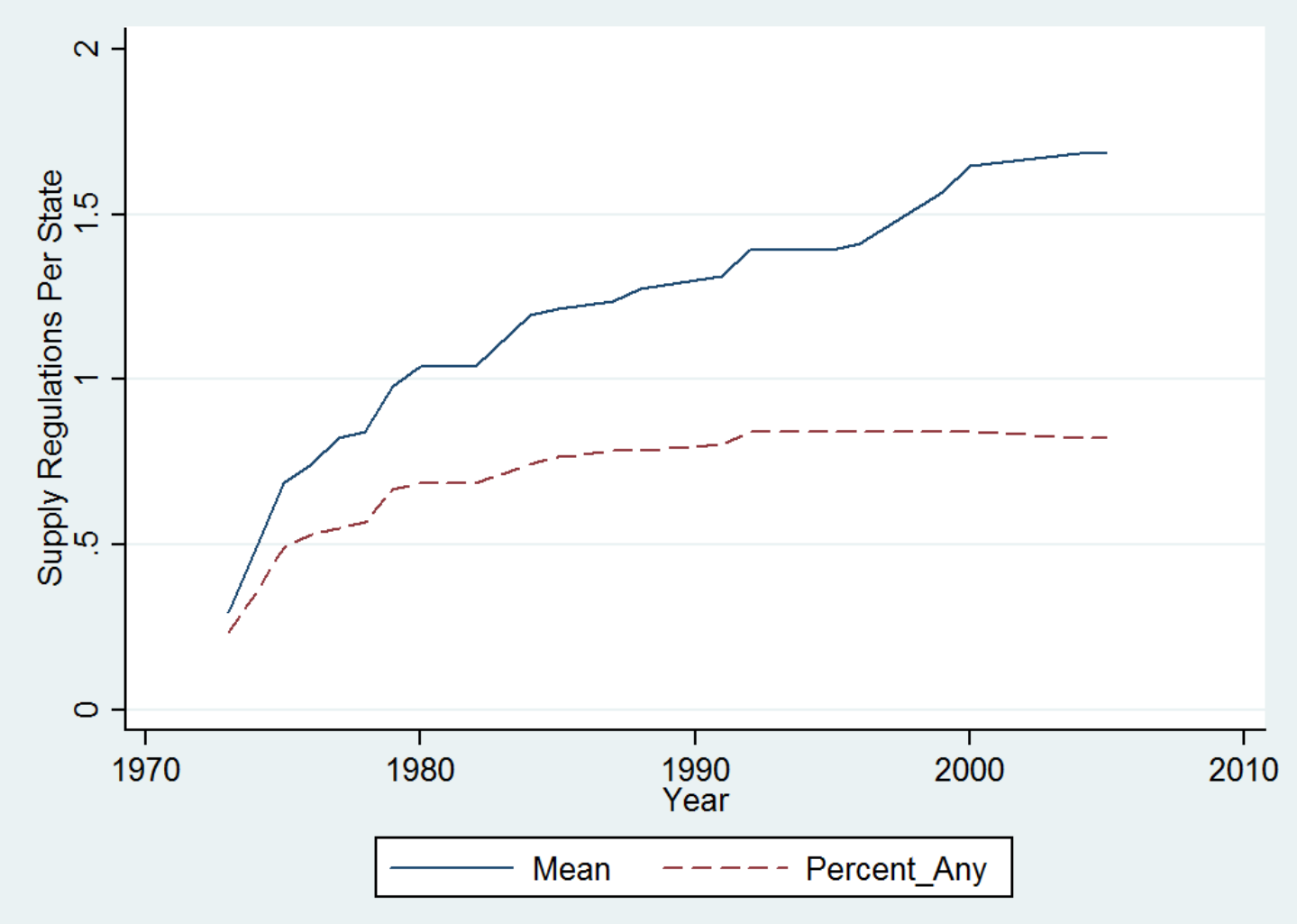

Note: Figure plots the number of regulations focused on abortion providers per state, and the fraction states with any such regulation. 
Figure 2: Procedures and Providers
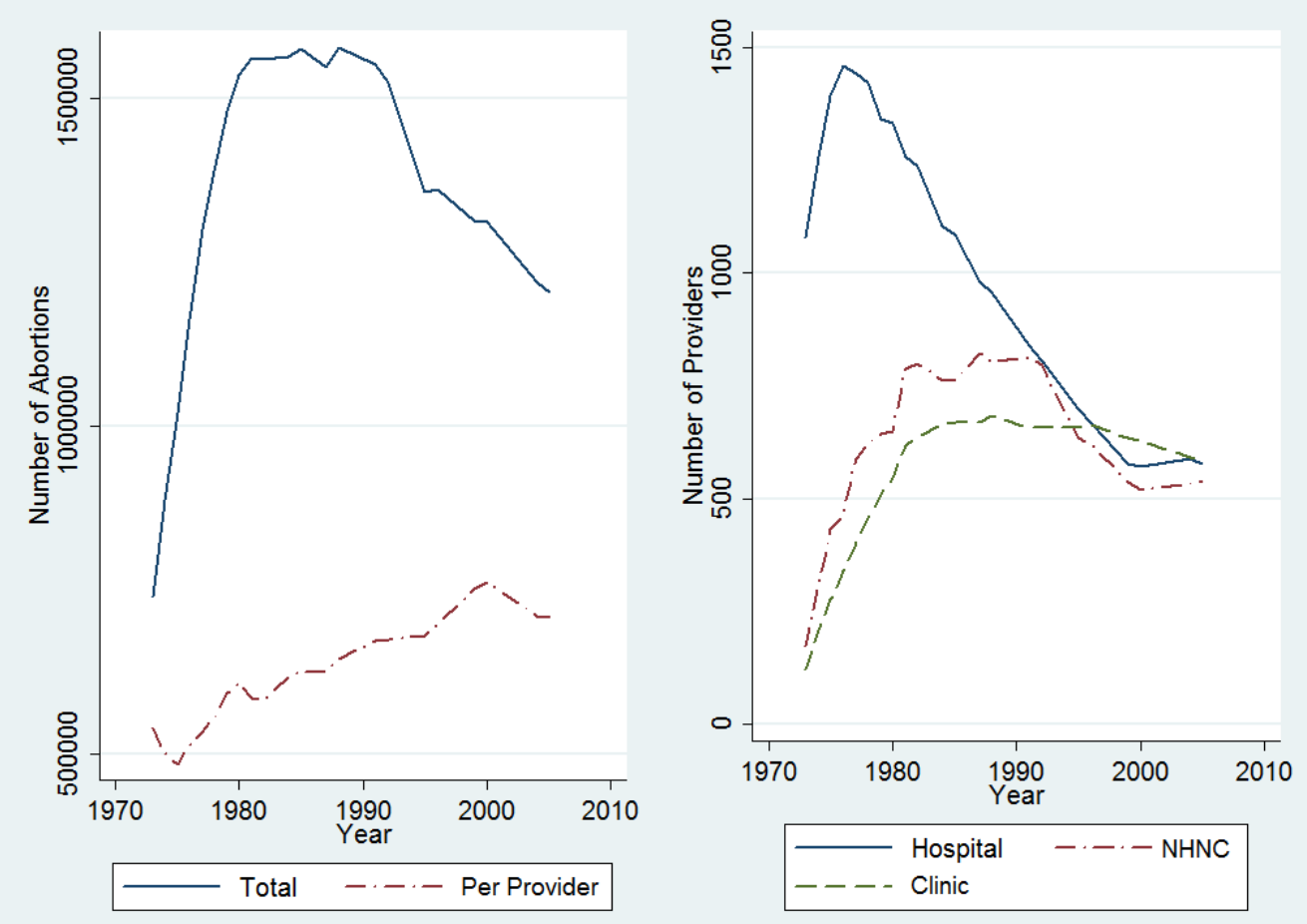

Note: Left panel plots the overall number of abortions and the number of procedures per provider times 100,000. The right panel plots the number of Hospital, NHNC and Clinic providers over time. 
Figure 3: Number of Providers Observed and Model Predictions

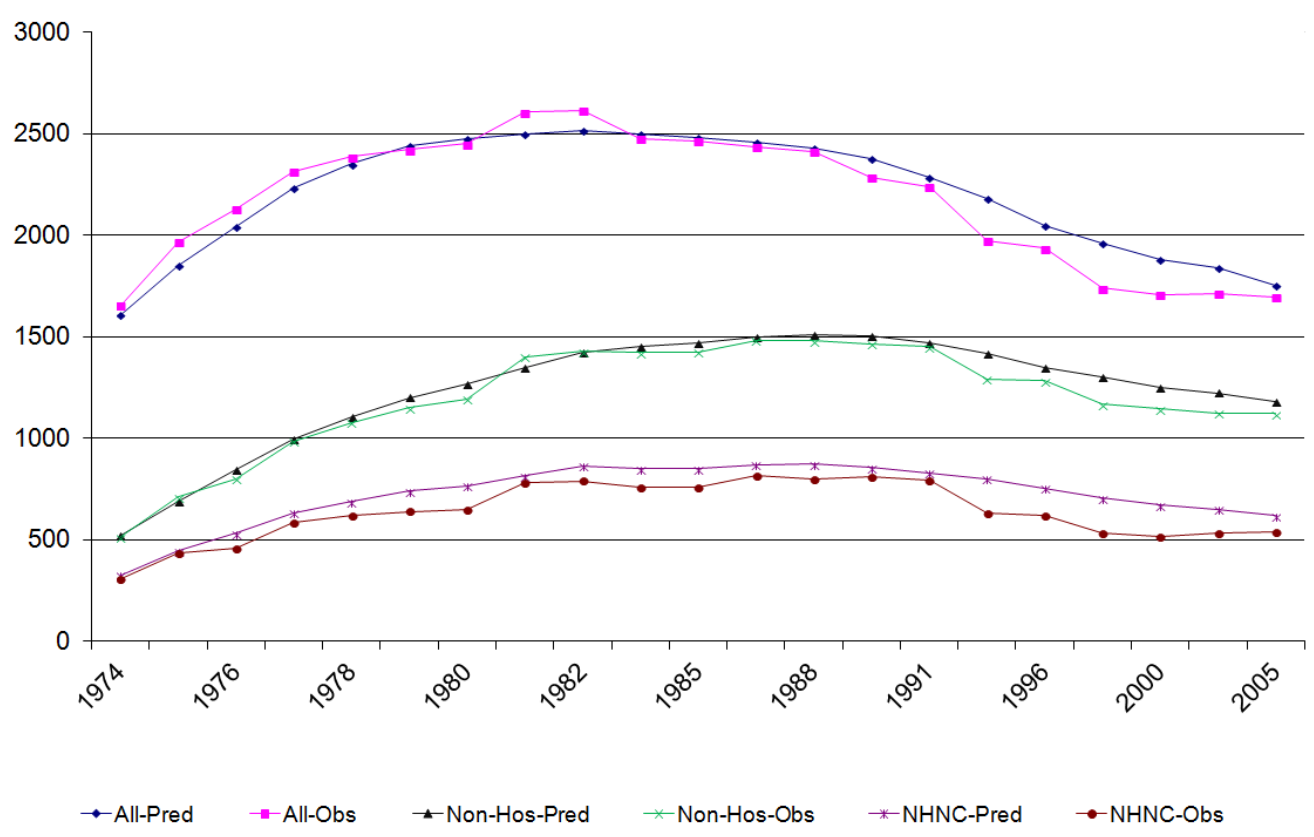

Note: Figure plots the number of observed and model predicted providers from the average of 50 simulations of the model, with 1973 numbers fixed to the observed and omitted.

Figure 4: Market Shares: Observed and Model Predictions

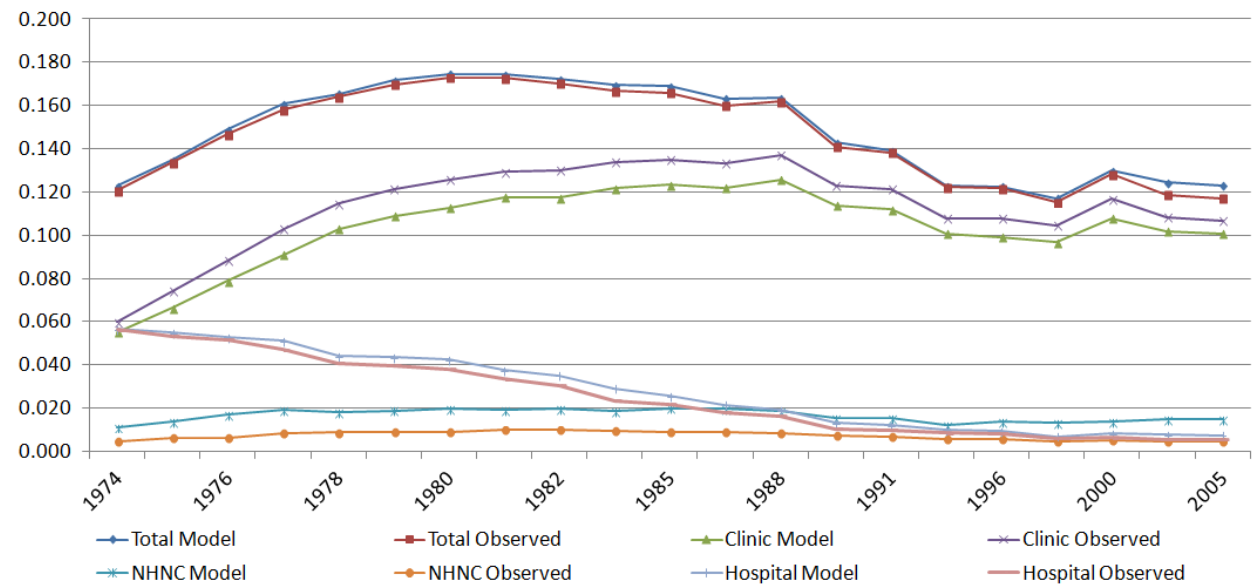

Note: Figure plots the market shares of each type of provider for all markets. 
Figure 5: Market Shares: Large Markets

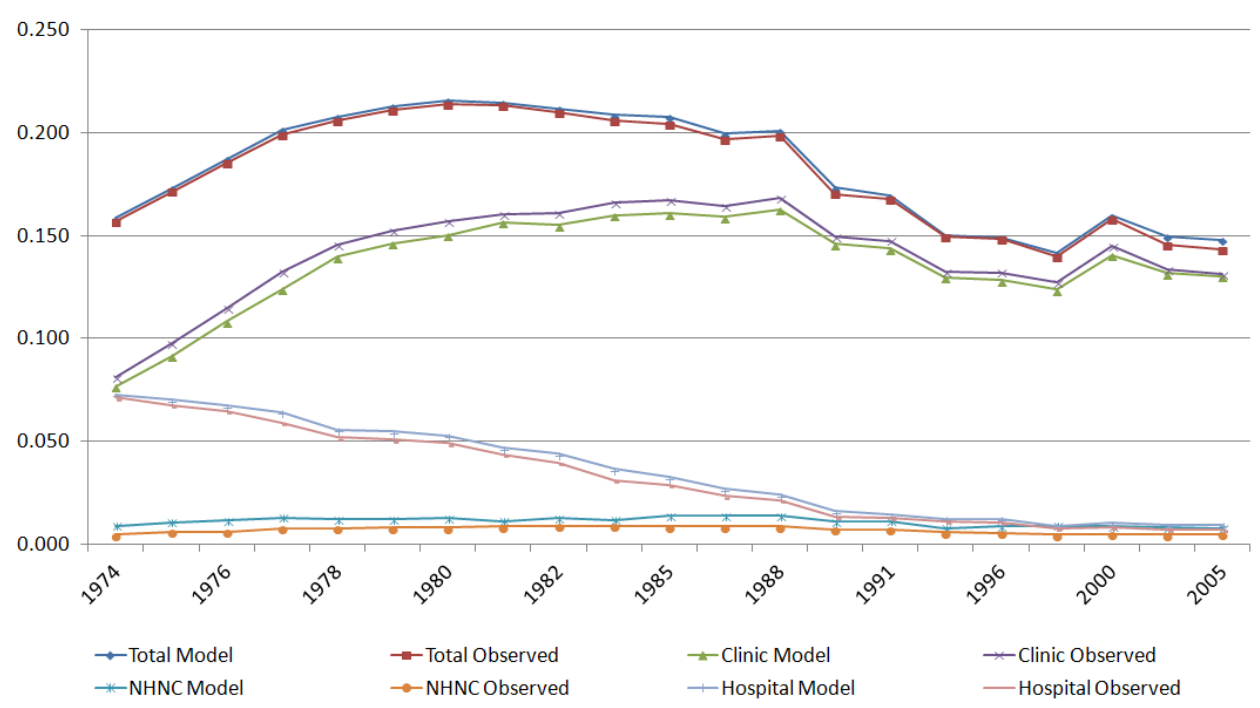

Note: Figure plots the market shares of each type of provider for only markets with greater than 4900 abortions (ever), which are the largest $10 \%$ of markets. 


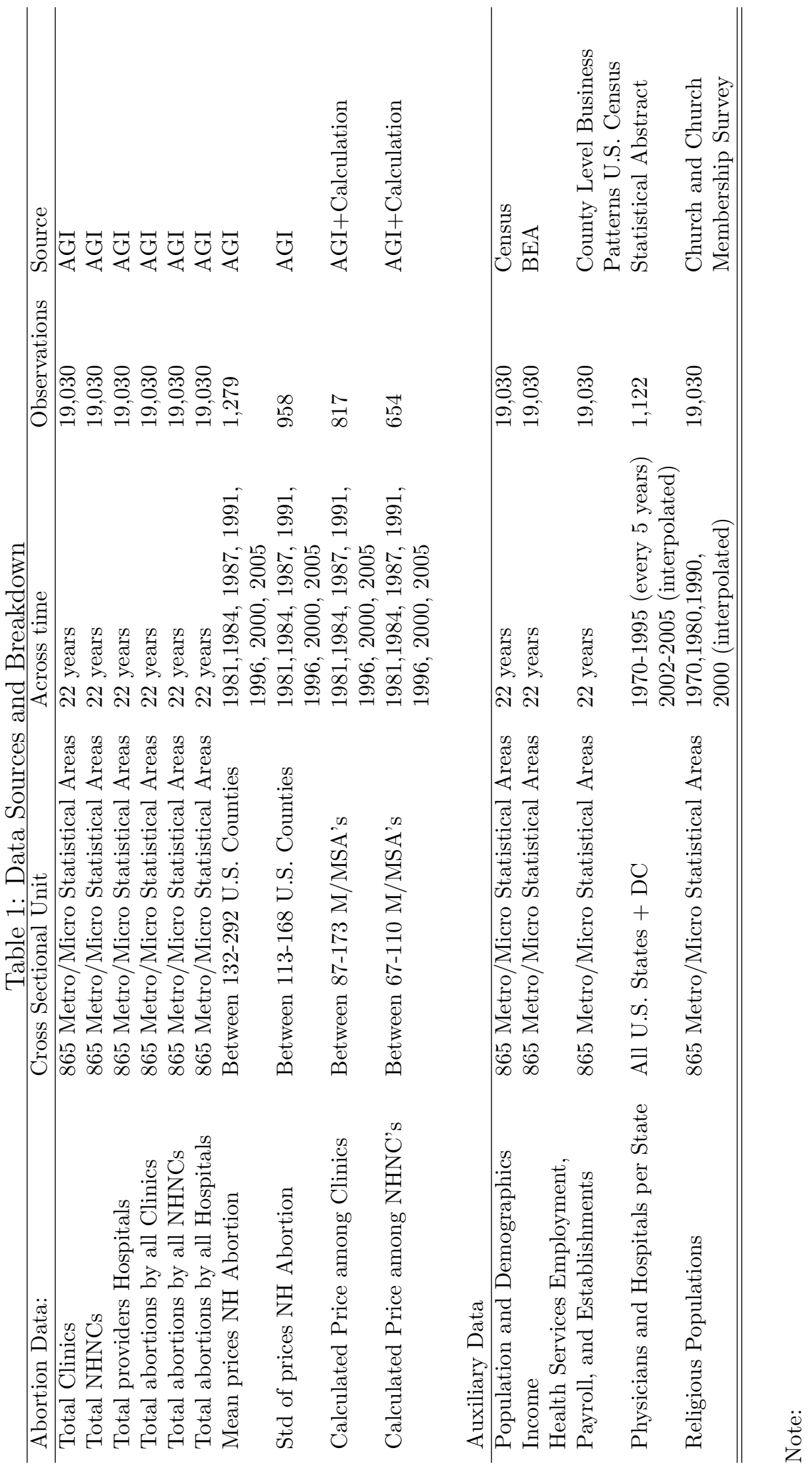


Table 2: Descriptive Statistics

\begin{tabular}{lcccc}
\hline Number of MSA's with Providers & 1975 & 1985 & 1995 & 2005 \\
\hline NHNC & 132 & 206 & 156 & 119 \\
Clinic & 113 & 193 & 186 & 193 \\
Hospital & 367 & 289 & 195 & 154 \\
& & & & \\
$N_{f}=1$ & & & & \\
\hline NHNC & 78 & 122 & 94 & 67 \\
Clinic & 67 & 93 & 93 & 117 \\
Hospital & 262 & 179 & 124 & 95 \\
& & & & \\
Percent of Total Services $\mid>$ 1000 Procedures & & & & \\
\hline NHNC & 6.48 & 5.76 & 4.24 & 3.00 \\
Clinic & 58.39 & 86.62 & 91.98 & 94.49 \\
Hospital & 35.13 & 7.62 & 3.78 & 2.52 \\
& & & & \\
Number of Providers $\mid>$ 1000 Procedures & & & & \\
\hline Mean & & & & \\
NHNC & 3.28 & 4.07 & 3.60 & 3.18 \\
Clinic & 2.36 & 3.94 & 4.10 & 3.64 \\
Hospital & 9.69 & 5.60 & 4.05 & 3.54 \\
& & & & \\
Price for 10 Week Procedure & 1974 & 1984 & 1996 & 2005 \\
\hline Imputed NHNC Mean & - & 548 & 577 & 614 \\
Imputed Clinic Mean & - & 361 & 358 & 399 \\
Observed Mean & - & 460 & 457 & 468 \\
$\sigma$ Across & - & 105 & 106 & 164 \\
$\sigma$ Within & - & 109 & 106 & 115 \\
\hline \hline
\end{tabular}

Note: All prices are in 2005 dollars. Sample is the 865 MSAs over time. 


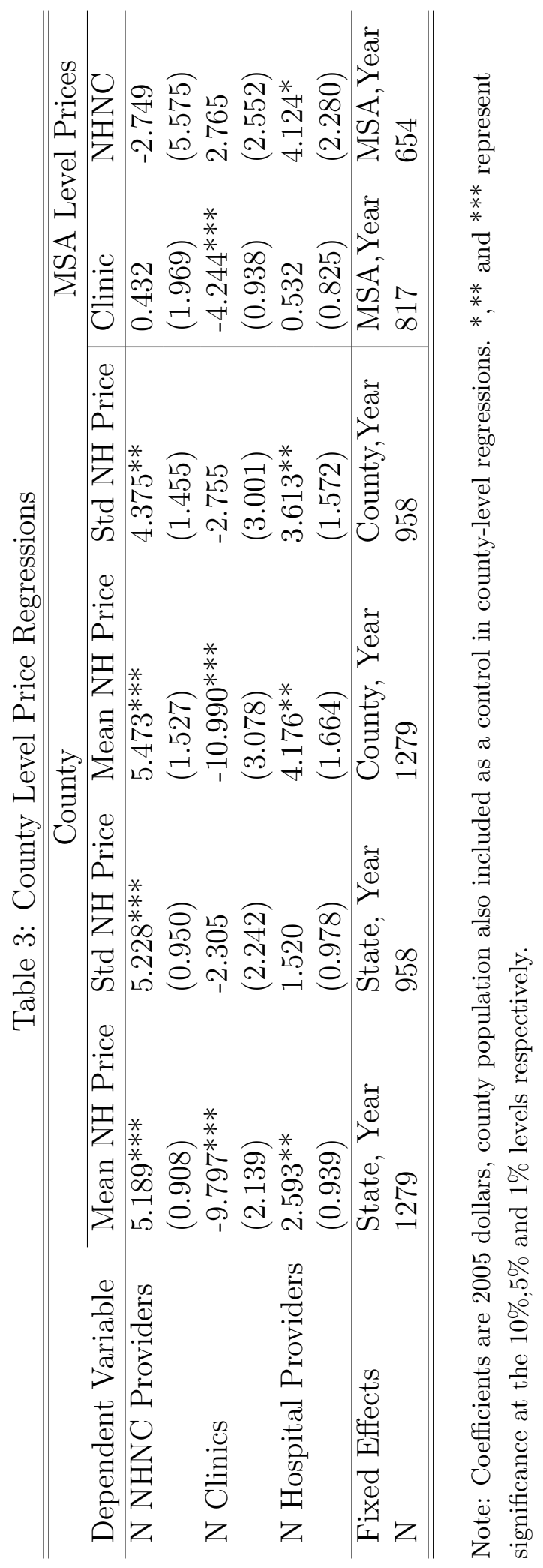


Table 4: State Law Implementation Years

\begin{tabular}{|c|c|c|c|c|c|c|}
\hline State & License & Physician Law & 2nd Trim. Hosp. & Locate $\mathrm{H}$ & Agree. $\mathrm{H}$ & Physical/Admin. \\
\hline $\mathrm{AL}$ & 1982 & 2002 & & & & 2002 \\
\hline $\mathrm{AK}$ & 1970(r 1981) & 1970 & & & & \\
\hline $\mathrm{AZ}$ & 1999 & 1984 & & & & 1999 \\
\hline $\mathrm{AR}$ & 1983 & 1983 & 1999 & & & 1999 \\
\hline $\mathrm{CO}$ & & 1967 & & & & \\
\hline CT & 1983 & 1974(r 2001) & & & & 1995 \\
\hline $\mathrm{DE}$ & & 1969 & & & & \\
\hline FL & 1978 & 1979 & 2005 & & & \\
\hline GA & & 1968 & 1974 & & & \\
\hline $\mathrm{HI}$ & & 1970 & & & & \\
\hline ID & & 1973 & & & & \\
\hline $\mathrm{IL}$ & 1973 & 1979 & & & & \\
\hline IN & 2005 & 1959 & 1973 & & & \\
\hline IA & & 1976 & & & & \\
\hline $\mathrm{KY}$ & 1982 & 1974 & & & 1998 & \\
\hline LA & 2001 & 1978 & & & & 2003 \\
\hline ME & & 1979 & & & & \\
\hline MD & & 1991 & & & & \\
\hline MA & & 1974 & & & & \\
\hline MI & 1978 & 1973 & & & & \\
\hline $\mathrm{MN}$ & 1974 & 1974 & & & & \\
\hline MS & 1991 & 1953 & 1996 & & & 1991 \\
\hline $\mathrm{MO}$ & 1987 & 1974 & & 2005 & & 1987 \\
\hline $\mathrm{NE}$ & & 1978 & & & & \\
\hline $\mathrm{NV}$ & & 1973 & 1973 & & & \\
\hline NJ & & 1978 & 1978 & & & \\
\hline NM & & 1969 & & & & \\
\hline NY & & 1965 & & & & \\
\hline $\mathrm{NC}$ & 1967 & 1967 & 1967 & & & 1976 \\
\hline $\mathrm{ND}$ & & 1975 & & & & \\
\hline $\mathrm{OH}$ & & 1974 & & & 1996 & \\
\hline OK & & 1978 & & & & \\
\hline $\mathrm{PA}$ & 2002 & 1982 & & & 1983 & 1983 \\
\hline $\mathrm{RI}$ & 1973 & 1973 & 1973 & & & \\
\hline $\mathrm{SC}$ & 1995 & 1974 & 1974 & & & 1996 \\
\hline SD & 2006 & 1973 & 2006 & & & \\
\hline $\mathrm{TN}$ & 1998(r 2001) & 1989 & & & & \\
\hline $\mathrm{TX}$ & 1989 & 1985 & & & & 1997 \\
\hline UT & 1981 & 1973 & & 1998 & 1998 & \\
\hline VA & & 1975 & 1975 & & & \\
\hline WA & & 1991(r 2004) & & & & \\
\hline WI & & 1956 & & 1976 & 1976 & \\
\hline $\mathrm{WY}$ & & 1977 & & & & \\
\hline
\end{tabular}

Note: States not mentioned had no effective supply-side regulations. 
Table 5: Quantity and Price Regressions

\begin{tabular}{|c|c|c|c|c|c|}
\hline & \multicolumn{3}{|c|}{ Quantity } & \multicolumn{2}{|c|}{$\log ($ Price $)$} \\
\hline & NHNC & Hosptial & Clinic & NHNC & Clinic \\
\hline \multirow[t]{2}{*}{ Agreement with $\mathrm{H}$} & 54.74 & $-351.30^{*}$ & 417.01 & $-0.3108^{*}$ & $-0.1636^{*}$ \\
\hline & $(99.80)$ & (175.19) & $(785.81)$ & $(.103)$ & $(.044)$ \\
\hline \multirow[t]{2}{*}{ Locate Near H } & $-430.23^{*}$ & 197.52 & -1216.66 & - & 0.0997 \\
\hline & $(201.085)$ & $(519.940)$ & $(1473.429)$ & & $(.088)$ \\
\hline \multirow[t]{2}{*}{ Physician Law } & $-119.34^{*}$ & -173.68 & -700.98 & $0.1295^{*}$ & 0.0234 \\
\hline & $(59.567)$ & $(135.920)$ & $(368.658)$ & $(.044)$ & $(.049)$ \\
\hline \multirow[t]{2}{*}{ 2nd Trimester } & 29.74 & 487.79 & 687.26 & 0.0164 & 0.1860 \\
\hline & (126.36) & $(341.92)$ & $(1453.49)$ & $(.225)$ & $(.191)$ \\
\hline \multirow[t]{2}{*}{ License } & -31.09 & 88.94 & -107.17 & -0.0384 & -0.0396 \\
\hline & $(60.65)$ & (180.02) & $(438.83)$ & $(.072)$ & $(.045)$ \\
\hline \multirow[t]{2}{*}{ Physical/Admin } & $127.69^{*}$ & -174.29 & $-752.47^{*}$ & $0.1909^{*}$ & 0.0550 \\
\hline & (59.61) & (138.38) & $(363.45)$ & $(.086)$ & $(.064)$ \\
\hline \multirow[t]{2}{*}{ Parental Consent } & 32.94 & -96.79 & 333.07 & 0.1295 & -0.0873 \\
\hline & $(57.60)$ & (138.07) & $(322.49)$ & $(.075)$ & $(.043)$ \\
\hline \multirow[t]{2}{*}{ Waiting Period } & 52.81 & -224.11 & 287.80 & 0.0581 & -0.0582 \\
\hline & $(58.46)$ & $(156.03)$ & $(346.59)$ & $(.098)$ & $(.047)$ \\
\hline \multirow[t]{2}{*}{ Parental Notification } & 12.52 & -275.80 & 398.82 & $-0.1841^{*}$ & -0.0664 \\
\hline & $(50.60)$ & $(166.46)$ & $(404.23)$ & $(.065)$ & $(.044)$ \\
\hline \multirow[t]{2}{*}{ Public Funding } & 54.89 & $167.06^{*}$ & 166.69 & -0.0963 & 0.0328 \\
\hline & $(34.57)$ & $(77.25)$ & $(226.71)$ & $(.079)$ & $(.049)$ \\
\hline Pseudo- $\mathrm{R}^{2} / R^{2}$ & .141 & .132 & .190 & 0.546 & 0.4347 \\
\hline $\mathrm{N}$ & 19030 & 19030 & 19030 & 657 & 819 \\
\hline Fixed Effects & State & State & State & State & State \\
\hline Trend & State-Linear & State-Linear & State-Linear & State-Linear & State-Linear \\
\hline State Variables & All & All & All & All & All \\
\hline
\end{tabular}

Note: Observations are market-years. Quantity coefficients from Tobit regression, price coefficients from $\log$ (price) linear regression. Each column is a separate regression. Standard errors clustered at the state level. 
Table 6: Entry and Exit Logit-Mixture Model

\begin{tabular}{|c|c|c|c|}
\hline Entry & NHNC & Clinic & Hospital \\
\hline \multirow{2}{*}{ Physical/Admin. Req's } & 0.009 & -0.374 & -0.060 \\
\hline & $(.225)$ & $(.224)$ & $(.249)$ \\
\hline \multirow[t]{2}{*}{ Provider License } & $-0.360^{* *}$ & $-0.336^{* *}$ & 0.012 \\
\hline & $(.114)$ & $(.137)$ & $(.137)$ \\
\hline \multirow[t]{2}{*}{ 2nd Trimester Hosp. } & 0.144 & $0.897^{* *}$ & 0.127 \\
\hline & $(.227)$ & $(.199)$ & $(.313)$ \\
\hline \multirow[t]{2}{*}{ Physician Law } & $-0.353^{* *}$ & $-1.004^{* *}$ & $-0.218^{*}$ \\
\hline & $(.088)$ & $(.103)$ & $(.116)$ \\
\hline \multirow[t]{2}{*}{ Locate Near Hosp. } & -0.607 & -0.402 & -0.191 \\
\hline & $(.646)$ & $(.546)$ & $(.614)$ \\
\hline \multirow[t]{2}{*}{ Agreement with Hosp. } & -0.331 & $0.812^{* *}$ & 0.063 \\
\hline & $(.368)$ & $(.343)$ & $(.399)$ \\
\hline \multicolumn{4}{|l|}{ Incumbency } \\
\hline \multirow[t]{2}{*}{ Physical/Admin. Req's } & 0.251 & 0.035 & -0.036 \\
\hline & $(.225)$ & $(.192)$ & $(.264)$ \\
\hline \multirow[t]{2}{*}{ Provider License } & 0.041 & $-0.215^{*}$ & 0.108 \\
\hline & $(.125)$ & $(.117)$ & $(.156)$ \\
\hline \multirow[t]{2}{*}{ 2nd Trimester Hosp. } & 0.232 & 0.083 & $0.957^{* *}$ \\
\hline & $(.235)$ & $(.198)$ & $(.346)$ \\
\hline \multirow[t]{2}{*}{ Physician Law } & $-0.200^{*}$ & $0.232^{* *}$ & 0.126 \\
\hline & $(.101)$ & $(.102)$ & $(.142)$ \\
\hline \multirow[t]{2}{*}{ Locate Near Hosp. } & 0.075 & $1.104^{* *}$ & -0.138 \\
\hline & $(.611)$ & $(.512)$ & $(.659)$ \\
\hline \multirow[t]{2}{*}{ Agreement with Hosp. } & 0.347 & $-0.644^{* *}$ & 0.350 \\
\hline & $(.331)$ & $(.295)$ & $(.440)$ \\
\hline $\mathrm{N}$ & 18165 & 18165 & 18165 \\
\hline$-\log ($ like $)$ & 5903.9 & 6002.9 & 3720.5 \\
\hline Fixed Effects & State & State & State \\
\hline Trend & State-Linear & State-Linear & State-Linear \\
\hline State Variables & All & All & All \\
\hline
\end{tabular}

Note: Observations are market years. Standard errors are clustered at the state level. 
Table 7: OLS of Lagged Abortions on Policy Enactment

\begin{tabular}{|c|c|c|c|c|c|c|}
\hline \multirow[b]{2}{*}{ Enactment of } & \multicolumn{3}{|l|}{ Abortions } & \multicolumn{3}{|c|}{$\mathrm{W} /$ Controls } \\
\hline & NHNC & Clinic & Hospital & NHNC & Clinic & Hospital \\
\hline License & $\begin{array}{c}-0.0083^{*} \\
(0.0039)\end{array}$ & $\begin{array}{c}0.0007^{*} \\
(0.0003)\end{array}$ & $\begin{array}{c}-0.0001 \\
(0.0002)\end{array}$ & $\begin{array}{c}0.0158 \\
(0.0102)\end{array}$ & $\begin{array}{l}-0.0009 \\
(0.0011)\end{array}$ & $\begin{array}{c}0.0048 \\
(0.0027)\end{array}$ \\
\hline Physician Law & $\begin{array}{c}-0.0243^{*} \\
(0.0101)\end{array}$ & $\begin{array}{l}0.0018^{*} \\
(0.0008)\end{array}$ & $\begin{array}{l}-0.0002 \\
(0.0004)\end{array}$ & $\begin{array}{l}-0.0038 \\
(0.0258)\end{array}$ & $\begin{array}{l}-0.0003 \\
(0.0033)\end{array}$ & $\begin{array}{c}0.0072 \\
(0.0062)\end{array}$ \\
\hline \multicolumn{7}{|l|}{ Enactment of: } \\
\hline Parental Consent & $\begin{array}{c}-0.0102^{*} \\
(0.0033)\end{array}$ & $\begin{array}{l}0.0007^{*} \\
(0.0003)\end{array}$ & $\begin{array}{l}-0.0002 \\
(0.0002)\end{array}$ & $\begin{array}{c}-0.005 \\
(0.0098)\end{array}$ & $\begin{array}{c}-0.0002 \\
(0.0008)\end{array}$ & $\begin{array}{l}-0.0003 \\
(0.0017)\end{array}$ \\
\hline Parental Notification & $\begin{array}{c}-0.0063^{*} \\
(0.0026)\end{array}$ & $\begin{array}{c}0.0005^{*} \\
(0.0002)\end{array}$ & $\begin{array}{l}-0.0002 \\
(0.0002)\end{array}$ & $\begin{array}{c}0.0189 \\
(0.0207)\end{array}$ & $\begin{array}{c}-2.00 \mathrm{E}-05 \\
(0.0006)\end{array}$ & $\begin{array}{c}0.0006 \\
(0.0017)\end{array}$ \\
\hline Waiting Period & $\begin{array}{c}-0.0058^{*} \\
(0.0025)\end{array}$ & $\begin{array}{l}0.0004^{*} \\
(0.0002)\end{array}$ & $\begin{array}{c}-0.0003 \\
(0.0003)\end{array}$ & $\begin{array}{c}0.0177 \\
(0.0107)\end{array}$ & $\begin{array}{l}-0.0015 \\
(0.0009)\end{array}$ & $\begin{array}{l}3.00 \mathrm{E}-05 \\
(0.0029)\end{array}$ \\
\hline Public Funding & $\begin{array}{l}0.0254^{*} \\
(0.0123)\end{array}$ & $\begin{array}{l}-0.0002 \\
(0.0005) \\
\end{array}$ & $\begin{array}{c}0.001 \\
(0.0010) \\
\end{array}$ & $\begin{array}{l}0.0668^{*} \\
(0.0287)\end{array}$ & $\begin{array}{c}0.0022 \\
(0.0024) \\
\end{array}$ & $\begin{array}{c}0.0032 \\
(0.0086) \\
\end{array}$ \\
\hline Fixed Effects & None & None & None & State & State & State \\
\hline State Variables & None & None & None & All & All & All \\
\hline
\end{tabular}

Note: The unit of observation is a state-year. The dependent variable is an indicator for a legal change, the independent variables are the laggaed total number of abortions by each provider type. Abortions are measured (in 1000s) in the period prior(or closest) to the policy change .

Observations are state-years, standard errors are clustered at the state level. State Variables are listed in the footnote 47. 
Table 8: Demand Estimates

\begin{tabular}{|c|c|c|c|c|}
\hline \multirow[b]{2}{*}{ Demand Parameters: } & \multicolumn{4}{|c|}{ Model } \\
\hline & OLS & IV & IV-NL & IV-NL with UH \\
\hline$\alpha_{1}$ & $\begin{array}{c}-0.00051^{*} \\
(0.0003)\end{array}$ & $\begin{array}{c}-0.0011^{* *} \\
(0.0005)\end{array}$ & $\begin{array}{c}-0.0011^{* *} \\
(0.0005)\end{array}$ & $-0.0007^{*}$ \\
\hline$\alpha_{2}$ & & & & $-0.0009 * *$ \\
\hline$\alpha_{3}$ & & & & $-0.0008^{* *}$ \\
\hline $1-\lambda_{1}$ & & & $\begin{array}{c}0.8489^{* *} \\
(0.213)\end{array}$ & $0.9343^{* *}$ \\
\hline $1-\lambda_{2}$ & & & & $0.9065^{* *}$ \\
\hline $1-\lambda_{3}$ & & & & $0.8827^{* *}$ \\
\hline \multicolumn{5}{|l|}{ Clinic Policy Effects } \\
\hline Waiting Period & $\begin{array}{c}-0.153^{* *} \\
(0.074)\end{array}$ & $\begin{array}{c}-0.161^{* *} \\
(0.073)\end{array}$ & $\begin{array}{c}-0.179^{* *} \\
(0.074)\end{array}$ & $-0.1650^{* *}$ \\
\hline Parental Consent & $\begin{array}{l}-0.071 \\
(0.069)\end{array}$ & $\begin{array}{c}-0.094 \\
(0.070)\end{array}$ & $\begin{array}{c}-0.141^{*} \\
(0.073)\end{array}$ & $-0.1804^{*}$ \\
\hline Parental Notification & $\begin{array}{l}-0.015 \\
(0.057)\end{array}$ & $\begin{array}{l}-0.002 \\
(0.058)\end{array}$ & $\begin{array}{c}0.125 \\
(0.082)\end{array}$ & 0.1163 \\
\hline Public Funding & $\begin{array}{c}0.012 \\
(0.066)\end{array}$ & $\begin{array}{c}0.017 \\
(0.069)\end{array}$ & $\begin{array}{c}0.032 \\
(0.072)\end{array}$ & 0.0286 \\
\hline \multicolumn{5}{|l|}{ First Stage Estimates } \\
\hline Mean Prices & & & & \\
\hline $\begin{array}{l}\text { Nearby MSA's } \\
\text { X NHNC } \\
\text { Mean Hospital }\end{array}$ & & $\begin{array}{c}0.525^{* *} \\
(0.221)\end{array}$ & $\begin{array}{c}0.525^{* *} \\
(0.221)\end{array}$ & $0.548^{* *}$ \\
\hline Share-Nearby MSA's & & & $-0.348 * * *$ & $-0.321^{* * *}$ \\
\hline $\begin{array}{l}\text { X Hospital } \\
\text { Mean } N_{N H N C} \\
\text { Nearby MSA'sX Large }\end{array}$ & & & $\begin{array}{c}(0.082) \\
0.118^{* * *} \\
(0.034)\end{array}$ & $0.106^{* * *}$ \\
\hline Fixed Effects & State & State & State & State \\
\hline Trends & Region & Region & Region & Region \\
\hline
\end{tabular}

Note: Dependent variable is the difference in the logs of each provider-type share and the outside good-share; observations are market-years. ${ }^{*}, * *$ denote significance at the $10 \%$ and $5 \%$ level respectively. All regulations included in regressions(supply and demand); full listing of dependent variables in footnote 47 . 
Table 9: Marginal Cost Estimates

\begin{tabular}{|c|c|c|c|c|c|c|}
\hline \multirow[b]{3}{*}{ Regulations } & \multirow{2}{*}{\multicolumn{3}{|c|}{ NHNC }} & \multicolumn{3}{|c|}{ Clinic } \\
\hline & \multicolumn{2}{|r|}{$k=$} & & \multicolumn{3}{|c|}{$k=$} \\
\hline & 1 & 2 & 3 & 1 & 2 & 3 \\
\hline Agreement with $\mathrm{H}$ & $\begin{array}{l}-0.073 \\
(0.084)\end{array}$ & $\begin{array}{c}-0.078 \\
(0.087)\end{array}$ & $\begin{array}{c}-0.088 \\
(0.093)\end{array}$ & $\begin{array}{c}0.014 \\
(0.047)\end{array}$ & $\begin{array}{c}0.013 \\
(0.050)\end{array}$ & $\begin{array}{c}0.010 \\
(0.056)\end{array}$ \\
\hline Physician Law & $\begin{array}{c}-0.091^{* *} \\
(0.034)\end{array}$ & $\begin{array}{c}-0.094^{* *} \\
(0.035)\end{array}$ & $\begin{array}{c}-0.099^{* *} \\
(0.037)\end{array}$ & $\begin{array}{c}0.090^{* *} \\
(0.025)\end{array}$ & $\begin{array}{c}0.095^{* *} \\
(0.026)\end{array}$ & $\begin{array}{c}0.106^{* *} \\
(0.030)\end{array}$ \\
\hline 2nd Trimester & $\begin{array}{c}-0.137^{* *} \\
(0.054)\end{array}$ & $\begin{array}{c}-0.144^{* *} \\
(0.056)\end{array}$ & $\begin{array}{c}-0.159^{* *} \\
(0.059)\end{array}$ & $\begin{array}{l}-0.036 \\
(0.033)\end{array}$ & $\begin{array}{l}-0.041 \\
(0.035)\end{array}$ & $\begin{array}{l}-0.049 \\
(0.040)\end{array}$ \\
\hline License & $\begin{array}{c}0.052 \\
(0.037)\end{array}$ & $\begin{array}{c}0.051 \\
(0.039)\end{array}$ & $\begin{array}{c}0.049 \\
(0.041)\end{array}$ & $\begin{array}{c}0.045^{*} \\
(0.026)\end{array}$ & $\begin{array}{l}0.047^{*} \\
(0.027)\end{array}$ & $\begin{array}{l}0.051^{*} \\
(0.031)\end{array}$ \\
\hline Physical/Admin & $\begin{array}{l}-0.100 \\
(0.067)\end{array}$ & $\begin{array}{l}-0.101 \\
(0.070)\end{array}$ & $\begin{array}{l}-0.104 \\
(0.075)\end{array}$ & $\begin{array}{l}-0.026 \\
(0.038)\end{array}$ & $\begin{array}{l}-0.028 \\
(0.041)\end{array}$ & $\begin{array}{l}-0.031 \\
(0.046)\end{array}$ \\
\hline MC Shifters: & & & & & & \\
\hline Constant & $\begin{array}{c}6.441^{* *} \\
(0.064)\end{array}$ & $\begin{array}{c}6.413^{* *} \\
(0.066)\end{array}$ & $\begin{array}{c}6.366^{* *} \\
(0.071)\end{array}$ & $\begin{array}{c}5.623^{* *} \\
(0.035)\end{array}$ & $\begin{array}{l}5.579^{* *} \\
(0.037)\end{array}$ & $\begin{array}{c}5.499^{* *} \\
(0.042)\end{array}$ \\
\hline Physicians per Capita & $\begin{array}{c}0.016^{* *} \\
(0.007)\end{array}$ & $\begin{array}{c}0.017^{* *} \\
(0.007)\end{array}$ & $\begin{array}{c}0.018^{* *} \\
(0.007)\end{array}$ & $\begin{array}{c}0.004 \\
(0.003)\end{array}$ & $\begin{array}{c}0.004 \\
(0.003)\end{array}$ & $\begin{array}{c}0.005 \\
(0.003)\end{array}$ \\
\hline Hospitals per Capita & $\begin{array}{c}-0.120^{* *} \\
(0.024)\end{array}$ & $\begin{array}{c}-0.124^{* *} \\
(0.025)\end{array}$ & $\begin{array}{c}-0.133^{* *} \\
(0.027)\end{array}$ & $\begin{array}{c}0.012 \\
(0.008)\end{array}$ & $\begin{array}{c}0.012 \\
(0.008)\end{array}$ & $\begin{array}{c}0.012 \\
(0.009)\end{array}$ \\
\hline Health Services Emp & $\begin{array}{c}-0.029^{*} \\
(0.017)\end{array}$ & $\begin{array}{c}-0.031^{*} \\
(0.018)\end{array}$ & $\begin{array}{c}-0.033^{*} \\
(0.019)\end{array}$ & & & \\
\hline Health Services Emp ${ }^{2}$ & $\begin{array}{c}0.008^{* *} \\
(0.002)\end{array}$ & $\begin{array}{c}0.008^{* *} \\
(0.002)\end{array}$ & $\begin{array}{c}0.009^{* *} \\
(0.002)\end{array}$ & & & \\
\hline Year & $\begin{array}{c}-0.002 \\
(0.002)\end{array}$ & $\begin{array}{l}-0.003 \\
(0.002)\end{array}$ & $\begin{array}{l}-0.003 \\
(0.002)\end{array}$ & $\begin{array}{c}-0.001 \\
(0.002)\end{array}$ & $\begin{array}{c}-0.001 \\
(0.002)\end{array}$ & $\begin{array}{l}-0.001 \\
(0.002)\end{array}$ \\
\hline Physicians per Capita $^{2}$ & & & & $\begin{array}{c}-0.007^{* *} \\
(0.002)\end{array}$ & $\begin{array}{c}-0.007^{* *} \\
(0.002)\end{array}$ & $\begin{array}{c}-0.007^{* *} \\
(0.002)\end{array}$ \\
\hline Hospitals per Capita² $^{2}$ & & & & $\begin{array}{c}0.006^{* *} \\
(0.003)\end{array}$ & $\begin{array}{c}0.006^{* *} \\
(0.003)\end{array}$ & $\begin{array}{c}0.006^{* *} \\
(0.003)\end{array}$ \\
\hline Correlation parameters: & & & & & & \\
\hline$\sigma_{N H N C}$ & 0.335 & 0.347 & 0.371 & & & \\
\hline$\sigma_{\text {Clinic }}$ & 0.259 & 0.275 & 0.310 & & & \\
\hline$\sigma_{\text {Clinic }, N H N C}$ & -0.005 & -0.006 & -0.007 & & & \\
\hline Mean MC (\$) & 459.82 & 441.75 & 412.65 & 314.48 & 300.06 & 276.41 \\
\hline
\end{tabular}

Dependent variable is log of marginal revenue for providers for each type; observations are market-years. 
Table 10: Fixed Cost Estimates

\begin{tabular}{lcccc}
\hline \multirow{2}{*}{ Operation } & Entry & Operation & Entry \\
\cline { 2 - 5 } & 0.205 & -0.134 & 0.257 & 0.313 \\
Physical/Admin & $(0.267)$ & $(0.355)$ & $(0.313)$ & $(0.421)$ \\
License & $-0.294^{* *}$ & 0.060 & 0.119 & 0.275 \\
& $(0.150)$ & $(0.215)$ & $(0.204)$ & $(0.264)$ \\
2nd Trimester & -0.542 & $1.402^{* *}$ & -0.172 & -0.460 \\
& $(0.467)$ & $(0.586)$ & $(0.501)$ & $(0.484)$ \\
Physician Law & -0.036 & $-0.650^{* *}$ & -0.112 & 0.102 \\
& $(0.129)$ & $(0.165)$ & $(0.187)$ & $(0.226)$ \\
Hospital Nearby & 1.125 & -1.723 & 0.335 & 1.434 \\
& $(0.726)$ & $(1.117)$ & $(0.942)$ & $(1.250)$ \\
Agreement with H & -0.648 & 0.398 & 0.113 & -0.671 \\
& $(0.456)$ & $(0.695)$ & $(0.537)$ & $(0.864)$ \\
HS Establishments & $1.326^{* *}$ & 0.440 & -0.230 & $3.528^{* *}$ \\
HS Employment & $(0.369)$ & $(0.517)$ & $(0.442)$ & $(0.657)$ \\
& $3.126^{*}$ & -3.728 & 1.522 & $27.972^{* *}$ \\
Fraction in Poverty & $(2.053)$ & $(3.473)$ & $(2.540)$ & $(4.725)$ \\
Catholics and Southern Baptists & -0.317 & $-5.903^{* *}$ & -0.021 & -3.312 \\
& $(0.800)$ & $(1.040)$ & $(1.380)$ & $(1.674)$ \\
Religious Adherents & 0.250 & 0.777 & $-1.464^{* *}$ & $4.924^{* *}$ \\
& $(0.283)$ & $(0.505)$ & $(0.403)$ & $(0.730)$ \\
$1\{k=1\}$ & $-0.727^{* *}$ & -0.033 & $0.672^{*}$ & $-5.797^{* *}$ \\
& $(0.245)$ & $(0.437)$ & $(0.379)$ & $(0.672)$ \\
$1\{k=2\}$ & $1.427^{* *}$ & $-4.040^{* *}$ & $2.113^{* *}$ & $-3.547^{* *}$ \\
Constant & $(0.105)$ & $(0.147)$ & $(0.149)$ & $(0.185)$ \\
& $-1.223^{* *}$ & $-0.912^{* *}$ & -0.064 & $0.461^{* *}$ \\
Fixed Effects & $(0.092)$ & $(0.174)$ & $(0.120)$ & $(0.153)$ \\
\hline \hline & $1.559^{* *}$ & $-4.085^{* *}$ & $1.925^{* *}$ & $-7.660^{* *}$ \\
& $(0.409)$ & $(0.449)$ & $(0.594)$ & $(0.641)$ \\
\hline
\end{tabular}

Note: $* * *$ indicate significance at the $10 \%$ and $5 \%$ levels respectively. Observations are market-years. Coefficients are in millions of 2005 constant dollars. 


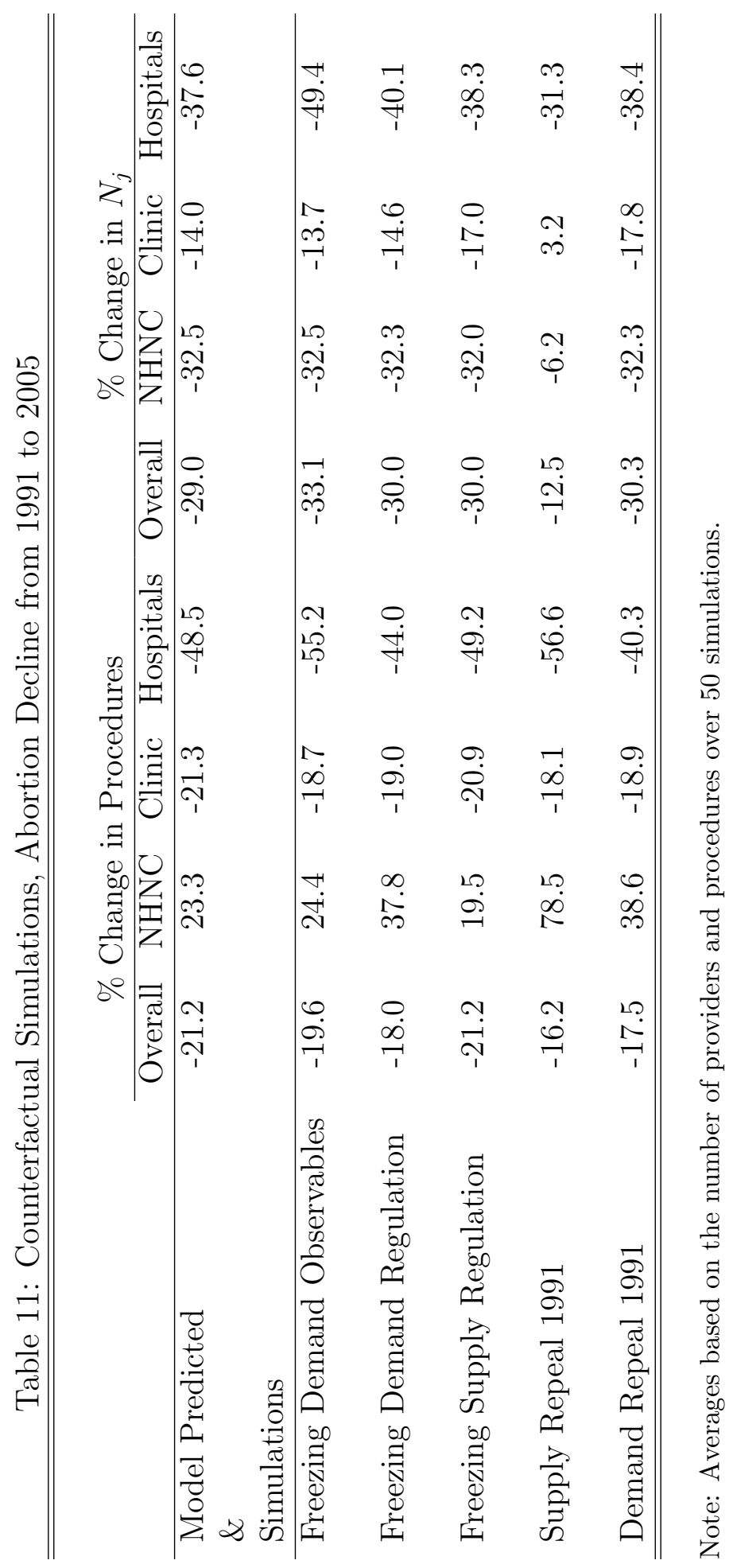


Table 12: Counterfactual Access Change from 1991 to 2005

\begin{tabular}{cccc}
\hline \hline Year & Model Predicted & Supply Repeal & Demand Repeal \\
\hline 1991 & 0.634 & 0.634 & 0.634 \\
1992 & 0.629 & 0.628 & 0.632 \\
1995 & 0.634 & 0.616 & 0.636 \\
1996 & 0.651 & 0.635 & 0.650 \\
1999 & 0.678 & 0.644 & 0.676 \\
2000 & 0.681 & 0.638 & 0.681 \\
2004 & 0.697 & 0.657 & 0.699 \\
2005 & 0.715 & 0.671 & 0.716 \\
\hline \hline
\end{tabular}

Note: Table gives the annual fraction of MSAs in the sample with no abortion providers. 
Table 13: Counterfactual, Imposing Utah Policies from 1976-2005

\begin{tabular}{lcccc}
\hline \hline & & & & \\
\% Change in Abortions & Total & NHNC & Clinic & Hospital \\
\hline 1976 & -0.37 & 15.62 & 1.03 & -4.33 \\
1991 & -0.85 & -0.41 & -1.05 & 0.98 \\
2005 & 9.77 & -44.35 & 12.20 & 37.15 \\
Avg Annual ', '05 & 0.25 & -11.34 & 1.54 & 3.96 \\
Avg Annual '01.06 & 3.00 & -27.06 & 4.31 & 17.01 \\
\% Change in Providers & & & & \\
\hline 1976 & -7.12 & -12.89 & -11.47 & -3.81 \\
1991 & -28.20 & -44.07 & -14.17 & -24.63 \\
Av05 Annual & -6.46 & -53.65 & 25.41 & 12.76 \\
Avg Annual '91-'05 & -20.67 & -38.57 & -10.58 & -13.69 \\
& -19.87 & -49.14 & 0.87 & -9.40 \\
MSAs with No Provider & Baseline & UT Regime & & \\
\hline 1976 & 0.543 & 0.543 & & \\
1991 & 0.624 & 0.709 & & \\
Avg Annual & 0.769 & 0.724 & & \\
Avg Annual '91-'05 & 0.581 & 0.640 & & \\
\hline \hline
\end{tabular}

Note: Averages based on 50 simulations. Percentage changes are from the baseline model. Simulation uses the reduced-form probabilities of entry and exit to simulate the number of providers in each market across time, and the Bertrand-Nash model to simulate market shares and the number of procedures conditional on the average number of simulated firms in each market-year. 